Article

\title{
Applicability of Assessment Indices for Hanok-User Sensory Comfort Based on Visual and Tactile Comfort Evaluation Indicators
}

\author{
Seung-Ju Choe and Seung-Hoon Han *D
}

check for updates

Citation: Choe, S.-J.; Han, S.-H. Applicability of Assessment Indices for Hanok-User Sensory Comfort Based on Visual and Tactile Comfort Evaluation Indicators. Sustainability 2021, 13, 11511. https://doi.org/ $10.3390 /$ su132011511

Academic Editor: Miguel Amado

Received: 19 August 2021

Accepted: 15 October 2021

Published: 18 October 2021

Publisher's Note: MDPI stays neutral with regard to jurisdictional claims in published maps and institutional affiliations.

Copyright: (C) 2021 by the authors. Licensee MDPI, Basel, Switzerland. This article is an open access article distributed under the terms and conditions of the Creative Commons Attribution (CC BY) license (https:/ / creativecommons.org/licenses/by/ $4.0 /)$.
School of Architecture, Chonnam National University, Gwangju 61186, Korea; 198848@jnu.ac.kr

* Correspondence: hshoon@jnu.ac.kr; Tel.: +82-62-530-1646

\begin{abstract}
This study aimed to present an evaluation system to assess comfort that reflects the unique value of vernacular architecture. For this purpose, the background, purpose, evaluation items, and evaluation methods of Korean Standard-Basic Part: 6300-1, 2 (KS A 6300) were analyzed. As a result, the weakness was found in the KS system that there was no method to evaluate the user's human sensory comfort. To overcome this problem, the contents of KS A 6300-1, 2 were analyzed, and evaluation indices were categorized to assess the comfort of human sensory experience. A comfort assessment index was then derived to evaluate the visual and tactile comfort of the Korean traditional house by analyzing previous research and systems. To assess the possibility of using the Hanok evaluation system for the derived comfort indices, the actual building environmental and user data were collected for one year. Based on the previous step, Predicted Mean Vote (PMV) and Daylight Glare Probability (DGP) were calculated, and at the same time, a comparative analysis was conducted with the collected user data. As a result, DGP showed a tendency of changing user comfort and an error of 7 to $8 \%$ regardless of region, while PMV showed a tendency similar to the change in user discomfort response rate. Accordingly, it was concluded that each evaluation index could be used for the comfort evaluation of Hanok.
\end{abstract}

Keywords: vernacular architecture; Hanok; predicted mean vote (PMV); predicted percentage dissatisfied index (PPD); glare index; daylight glare probability (DGP)

\section{Introduction}

The international style of architecture emerged in the 18th century with the development of mass production systems due to industrialization. As a result, architecture in the 20th century emphasized standardization, uniformity, and universality [1]. This old tendency made the field of architecture ignore the importance of locality, location, climate, and environmental characteristics. Furthermore, the one-use resource consumption method caused serious environmental pollution, and attempts to solve this problem appeared only in the 1970s. In the architecture industry, various eco-friendly architectural trends have emerged that emphasize locality and location based on ecosystem monism to solve serious pollution problems. With this change in architectural trend, the status and value of vernacular architecture began to increase naturally $[2,3]$.

Vernacular architecture is a style of architecture in which regional characteristics, such as topography, climate, lifestyle, and culture, are reflected in the architecture. Furthermore, important concepts are reflected in traditional architecture form for a long time and inherited. Therefore, vernacular architecture can be seen to reflect the value of locality, which is emphasized in eco-friendly architecture, into a building, and as a hint to contemporarily reinterpret regional characteristics [1]. Building assessment systems in each country, such as LEED (Leadership in Energy and Environmental Design), can assess a target's pros and cons and account for regional characteristics of evaluation targets in evaluation process [1,4-6]. 
The Hanok is one of the vernacular architectural forms of Korea, and a representative wooden-structure architecture style. However, with the rapid spread of standardized houses with the New Village Movement in the 1970s, the traditional value of Korean architecture was lost. Notwithstanding, with the transition to modern society, the concept of well-being emerged, and eco-friendly residential spaces began to draw attention. Accordingly, the health benefits of the Hanok have attracted attention, and the preference for vernacular building is continuously increasing $[7,8]$.

Although the Korean Standard (KS) for estimating the comfort of Hanok space does not reflect traditional architecture value in the assessment system, the KS A 6300 'Hanok's comfort evaluation system' was stipulated in February 2017, and the building performance evaluation standards already registered with the KS were applied $[9,10]$. However, the evaluation system was not properly applied at the research stage of the Hanok comfort evaluation system. The reason for this problem is that the value of traditional building was not properly reflected in the process of applying it, and as a result, the standard of application was recklessly accepted. In addition, KS A 6300 cannot accurately assess human sensory comfort. In addition, there is no research aimed at optimizing human sensory indices for traditional Korean architecture from an institutional point of view. As a result of this problem, KS A 6300 cannot accurately assess human sensory comfort. Therefore, the evaluation system of traditional buildings needs to be supplemented by reflecting the quantitative comfort evaluation indices.

\section{Research Flow and Review of KS A $\mathbf{6 3 0 0}$}

\subsection{Research Steps}

This study aimed to overcome the limitations of the comfort evaluation system of the Hanok in terms of evaluation objectives, and at the same time reflect quantitative evaluation indicators that can evaluate human sensory comfort in the standard. Specifically, the quantitative comfort evaluation index that was officially used was searched and calculated by applying Hanok environmental data. In addition, after examining the traditionalhousing user assessment data, the calculated index and the user evaluation were compared with each other to analyze whether it was possible to derive a result that is similar to the actual comfort of the user. The contents were analyzed to review whether the selected evaluation factors could be reflected in the evaluation system of KS A 6300.

Figure 1 shows the order in which the research was conducted. As a first step, the evaluation items suggested by KS A 6300 were analyzed. Among the suggested evaluation items, indices having a direct relationship to human sensory comfort were classified. The evaluation indicator that could perform the comfort assessment according to the type of human sensory comfort required for each classified item was searched through prior research and institutional standards.

In the second stage, microclimate factors that affect human sensory comfort, such as temperature, humidity, MRT (Mean Radiant Temperature), and wind speed, were measured as environmental factors that could be measured on-site among environmental factors of Hanok. As a condition for data collection, a place where users could live or stay for a long time was selected. In addition, a one-year test was planned to secure all data for each time-point of the seasonal characteristics of Korea.

The third step was to compare and analyze selected comfort indicators and user assessment results by using the collected data. Specifically, we checked whether the comfort indicators could detect the comfort of Hanok users by comparing the trends and errors of the two data.

Lastly, by comprehensively reviewing environment comfort indicators, the possibility of application to KS A 6300 was reviewed. 


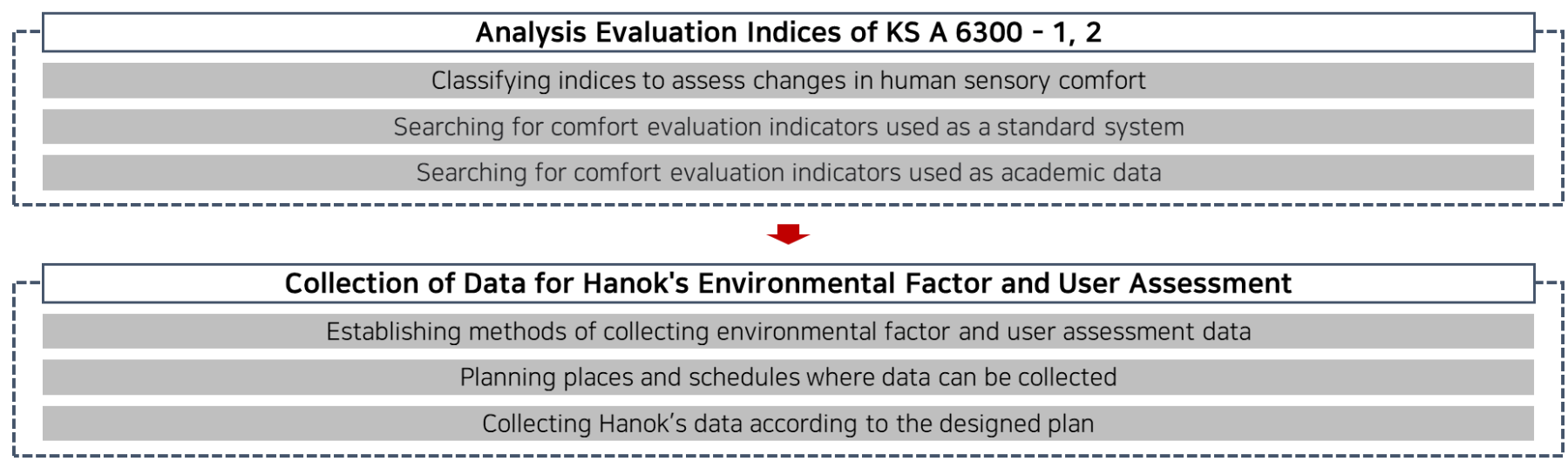

Selecting Target Buildings to Apply Sensory Evaluation Indicators and Measuring Environmental Data Selecting target buildings with similar environmental conditions

Identifying environmental data types of calculating sensory evaluation indicators Measuring environment data according to the collection plan

\begin{tabular}{|} 
Complementing the Hanok Evaluation System through the Comparison of Collected Data \\
Calculating quantitative comfort evaluation indices by using environmental data \\
Comparing quantitative comfort indices and user data \\
Reviewing the possibility of applying quantitative indices based on the comparison results \\
\hline Proposing the Hanok Comfort Evaluation System based on the Analysis Results \\
\hline
\end{tabular}

Figure 1. Research steps and flow.

\subsection{Analysis Evaluation Indices of KS A 6300}

The KS A 6300 standard is divided into "KS A 6300-1, Examination method for Hanok-Part 1: Comfort" and "KS A 6300-2, Examination method for Hanok-Part 2: Environmental Properties". In KS A 6300-1, evaluation items to evaluate vernacular building comfort were prepared, and in the appendix, the applied evaluation method is described. It is stated that the KS standard aims to present a comfort evaluation method and standard reflecting the characteristics of Korean traditional building $[9,10]$.

The evaluation items of KS A 6300-1 and 2 are divided into nine physical perception and five psychological cognition elements. The comprehensive comfort evaluation of the Hanok was performed through these items, and Table 1 presents the evaluation method for each item. The evaluation methods are divided into five categories of field measurement, sample test, computer simulation, calculation, and expert evaluation. For some items, more than two evaluation methods were introduced $[9,10]$. Air-tightness and sound insulation were evaluated only by field measurement. It was necessary to secure field data through measurement, because these factors are affected by the physical properties of the walls and windows of the Hanok. Second, solar radiation, solar lighting, and condensation used computer simulation as an evaluation tool to control climate conditions. Third, the performance of humidity control was measured in a laboratory by producing a sample that had the same physical properties as the building. Finally, for insulation, the heat transmission coefficient was calculated by using the physical property data written in the architectural specifications. In the case of air cleanliness and thermal comfort, a plurality of evaluation methods was used in parallel to evaluate comfort. The psychological cognition part evaluated the Hanok through a group of experts who could clearly explain the evaluation criteria. These series of methods had the weakness of being unable to 
evaluate the actual environment of the evaluation target. Since most of the evaluation targets were spaces where users live, destruction and damage for testing were limited. Therefore, evaluation is limited at the level of a questionnaire for the user's senses, and this method made it difficult to obtain quantitative data. In addition, over time, the data written in architecture-related papers are highly likely to be corrupted. Considering the purpose of the KS Hanok standard, it is necessary to collect environmental data through field surveys and to use quantitative indicators that can be directly evaluated.

Table 1. Category of KS A 6300-1 and 6300-2.

\begin{tabular}{|c|c|c|c|c|c|}
\hline Property & $\begin{array}{c}\text { Item } \\
\text { Number }\end{array}$ & Evaluation Item & $\begin{array}{c}\text { Content } \\
\text { Description Part }\end{array}$ & $\begin{array}{c}\text { Type of Evaluation } \\
\text { Method }\end{array}$ & $\begin{array}{l}\text { Applicable } \\
\text { Standards }\end{array}$ \\
\hline \multirow{21}{*}{$\begin{array}{l}\text { Physical } \\
\text { perception }\end{array}$} & 5.1 .1 & Humidity Control & KS A 6300-2 & Sample Test & KS F 2611 \\
\hline & 5.1 .2 & Air-Tightness & KS A 6300-2 & Field Measurement & KS L ISO 9972 \\
\hline & \multirow{3}{*}{5.1 .3} & \multirow{3}{*}{ Air cleanness } & \multirow{3}{*}{ KS A 6300-2 } & Field Measurement and & KS I ISO 16000-6 \\
\hline & & & & Sample Test & KS I ISO 16000-3 \\
\hline & & & & Sample Test & KS F 2295 \\
\hline & \multirow{3}{*}{5.1 .4} & \multirow{3}{*}{ Condensation } & \multirow{3}{*}{ KS A 6300-2 } & & KS L 9016 \\
\hline & & & & Computer Simulation & KS L ISO 8301 \\
\hline & & & & & ISO 15099 \\
\hline & \multirow{2}{*}{5.1 .5} & \multirow{2}{*}{ Insulation } & \multirow{2}{*}{ KS A 6300-1 } & \multirow{2}{*}{ Computer Calculation } & KS F 2277 \\
\hline & & & & & KS F 2278 \\
\hline & 5.1 .6 & $\begin{array}{c}\text { Solar } \\
\text { Radiation }\end{array}$ & KS A 6300-1 & Computer Simulation & -5 \\
\hline & \multirow[t]{4}{*}{5.1 .7} & \multirow[t]{5}{*}{ Thermal Comfort } & KS A 6300-1 & $\begin{array}{l}\text { Field Measurement and } \\
\text { Computer Calculation }\end{array}$ & KS A ISO 7730 \\
\hline & & & \multirow{8}{*}{ KS A 6300-1 } & \multirow{8}{*}{ Field Measurement } & KS C IEC 61672-1 \\
\hline & & & & & KS C 1505 \\
\hline & & & & & KS F 2863-1 \\
\hline & \multirow{5}{*}{5.1 .8} & & & & KS F 2863-2 \\
\hline & & \multirow{4}{*}{$\begin{array}{c}\text { Sound } \\
\text { Insulation }\end{array}$} & & & KS C IEC 60942 \\
\hline & & & & & KS C IEC 1260 \\
\hline & & & & & KS F 2862 \\
\hline & & & & & KS F 2810-1 \\
\hline & 5.1 .9 & Solar Lighting & KS A 6300-1 & Computer Simulation & $\begin{array}{c}\text { NS } 52010-2 \\
-\end{array}$ \\
\hline \multirow{5}{*}{$\begin{array}{l}\text { Psychological } \\
\text { Cognition }\end{array}$} & 5.2 .2 & Scenery & KS A 6300-1 & Expert Evaluation & - \\
\hline & 5.2 .3 & Beauty & KS A 6300-1 & Expert Evaluation & - \\
\hline & 5.2 .4 & Deodorization & KS A 6300-1 & Expert Evaluation & - \\
\hline & 5.2 .5 & Usability & KS A 6300-1 & Expert Evaluation & - \\
\hline & 5.2 .6 & Health & KS A 6300-1 & Expert Evaluation & - \\
\hline
\end{tabular}

However, it can be problematic that the separate KS certification indicators previously presented in seven of the total 14 items of KS A 6300 were indiscriminately applied without research according to the spatial characteristics of Hanok. Of course, if the assessment system of the applied KS standard is used as is, there should be a clear reason for this situation. However, KS A 6300 does not mention the reason for applying the existing standard of the KS to the evaluation method of the applicable standard. In particular, in the case of physical perception items, the KS system applied in the majority of items is applied in the same way. This situation has the potential to undermine the regulatory objectives of the Hanok standard. In addition, some categories of KS A 6300 used other existing KS evaluation methods that can evaluate building performance, but the results cannot directly assess user comfort. For this reason, the user comfort cannot be determined clearly using the applicable evaluation system. Among the applied KS items, the only item that can evaluate human sensory comfort is KS A ISO 7730 in the thermal comfort part. Excluding this, the evaluation method of eight physical perception items does not reflect human data, 
so the evaluation of comfort cannot be conducted. Therefore, the current KS A 6300 has limitations in terms of comfort evaluation.

One of the causes of the above problem is that the classification of the evaluation items presented in KS A 6300 is unclear. For example, thermal comfort performs an assessment of body warmth. On the other hand, insulation refers to the thermal-energy-blocking performance of a building to protect the indoor thermal environment. Both items use the same environmental factor, the column. However, thermal comfort evaluates the impact on the human senses, while insulation evaluates the blocking performance of the space. The attributes of the objects evaluated by the two categories are individual, but the KS standard classifies the two categories as the same attribute. As can be seen, in the current Hanok evaluation system, classification by item is mixed. Therefore, each evaluation item needs a reclassification process according to the attributes of the evaluation target. Table 2 shows that, based on this concept, the nine physical perception evaluation items were divided into spatial performance and human sensory evaluation fields. In the process of doing this, items that consider two evaluation fields together were classified based on the attributes of the final evaluation result.

Table 2. Reclassification evaluation item of KS A 6300-1 and 6300-2.

\begin{tabular}{|c|c|c|c|c|c|}
\hline Property & $\begin{array}{c}\text { Item } \\
\text { Number }\end{array}$ & Evaluation Item & Evaluation Target & $\begin{array}{l}\text { Evaluation Element } \\
\text { and Sense }\end{array}$ & $\begin{array}{l}\text { Reclassification } \\
\text { Category }\end{array}$ \\
\hline \multirow{9}{*}{$\begin{array}{l}\text { Physical } \\
\text { perception }\end{array}$} & 5.1 .1 & $\begin{array}{l}\text { Humidity } \\
\text { Control }\end{array}$ & Space Element & Wall, Floor, Roof & Space Performance \\
\hline & 5.1 .2 & Air-Tightness & Space Element & $\begin{array}{l}\text { Gap of Wall and } \\
\text { Window, etc. }\end{array}$ & \multirow{8}{*}{$\begin{array}{c}\text { Sensory } \\
\text { Performance } \\
\text { Space Performance } \\
\text { Space Performance } \\
\text { Sensory } \\
\text { Performance } \\
\text { Sensory } \\
\text { Performance } \\
\text { Sensory } \\
\text { Performance } \\
\text { Sensory } \\
\text { Performance }\end{array}$} \\
\hline & 5.1 .3 & Air cleanness & $\begin{array}{c}\text { Human } \\
\text { Sensory Element }\end{array}$ & Smell & \\
\hline & 5.1 .4 & Condensation & Space Element & Wall, Floor, Roof & \\
\hline & 5.1 .5 & Insulation & Space Element & Wall, Floor, Roof & \\
\hline & 5.1 .6 & Solar Radiation & $\begin{array}{c}\text { Human } \\
\text { Sensory Element }\end{array}$ & $\begin{array}{l}\text { Warmth } \\
\text { of the Skin }\end{array}$ & \\
\hline & 5.1 .7 & Thermal Comfort & $\begin{array}{c}\text { Human } \\
\text { Sensory Element }\end{array}$ & $\begin{array}{l}\text { Warmth } \\
\text { of the Skin }\end{array}$ & \\
\hline & 5.1 .8 & Sound Insulation & $\begin{array}{c}\text { Human } \\
\text { Sensory Element }\end{array}$ & Sound & \\
\hline & 5.1 .9 & Solar Lighting & $\begin{array}{c}\text { Human } \\
\text { Sensory Element }\end{array}$ & Vision & \\
\hline
\end{tabular}

Among the classified evaluation items, the area in which human sensory experience can be evaluated has the potential to present a suitable criterion for determining the comfort of the residence. The indicator can evaluate sensory experience by allowing direct comparison with the user's comfort. Accordingly, indices for evaluating human sensory experience were extracted. As a result, items for evaluating sensory comfort, such as sight, smell, tactile feeling, and hearing, were derived.

Next, among the derived evaluation items, the items in which spatial conditions have a high influence on the judgment of comfort were classified. The decision on hearing comfort has various variables, such as the location of the building, the context of the region, and the surrounding environment, as well as the sound insulation of the space. For example, even though the walls have the same physical properties, the noise generated in urban areas and rural areas is different, and the comfort of the noise may change accordingly. Conversely, even when evaluating the noise in an apartment in the same city center, there are various variables, such as the type of people around, and the distance from the stairs. Olfactory comfort also has as many variables as the auditory environment. This is because the senses of smell and hearing can feel unpleasant in response to instantaneous stimulation. Therefore, it is difficult to control variables to assess the comfort of the auditory and olfactory environments only with spatial conditions. However, if these are 
not controlled, the evaluation of comfort for the two human sensory experiences caused by spatial conditions cannot have meaning. Therefore, in this study, the evaluation of comfort in the auditory and olfactory fields was excluded, and finally, the items presented in Table 3 were selected as the final evaluation items.

Table 3. Final classified evaluation item of sensory performance in KS A 6300-1 and 6300-2.

\begin{tabular}{cccccc}
\hline Property & Item Number & Evaluation Item & Evaluation Factor & $\begin{array}{c}\text { Human Sense } \\
\text { Organs }\end{array}$ & $\begin{array}{c}\text { Sensory Comfort } \\
\text { Category }\end{array}$ \\
\hline Physical & 5.1 .6 & Solar Radiation & Warmth of the Skin & Skin & Tactile Comfort \\
perception & 5.1 .7 & Thermal Comfort & Warmth of the Skin & Skin & Tactile Comfort \\
& 5.1 .9 & Solar Lighting & Sight & Eyes & Visual Comfort \\
\hline
\end{tabular}

\section{Searching Sensory Comfort Evaluation Method \\ 3.1. Review of the Comfort Index}

As a result of analyzing the evaluation items of KS A 6300 in the previous research stage, it was found that there were some indices that indirectly evaluated the user's comfort in the KS Hanok standard. In addition, since some KS categories could not borrow a quantitative evaluation index that could directly evaluate the user's sense of comfort, research results suggested that it was necessary to search for an evaluation index that could evaluate the user's sense. However, if the process of calculating the selected comfort indicators was complicated or affected by diverse variables, the assessment could not be performed properly. In addition, since the comfort index needed to be applied to the KS, it needed to have a universality that was used in the estimation tools of other countries, such as BREEAM (Building Research Establishment Environmental Assessment Method), CASBEE (Comprehensive Assessment System for Building Environmental Efficiency), etc. [11,12]. In order to select an evaluation index that could meet the mentioned conditions, references related to comfort evaluation at home and abroad were searched. For the type of reference, research data in the field of visual and tactile comfort were reviewed, focusing on the study of indoor user comfort evaluation [13]. As a result, evaluation indicators, such as those presented in Table 4, were searched. However, the searched comfort indicators differed in the category of the evaluation target according to the indoor/outdoor space, and this study required the index that was mainly used for indoor evaluation. In addition, it needed to be able to be compared with user evaluation data. Therefore, the Comfort Index should be able to present changes in human sensory experience according to changes in values. Based on these conditions, Daylight Glare Probability (DGP) and Predicted Mean Vote (PMV) techniques were finally selected [14-17].

Table 4. Searched evaluation Indices of sensory comfort.

\begin{tabular}{cccc}
\hline Property & Sensory Comfort Category & Evaluation Index & Field of Application \\
\hline & & Operative Temperature & Basic Thermal Comfort \\
& PMV & Indoor Thermal Comfort \\
Physical & Tactile Comfort & Wet Bulb Glove Temperature & Outdoor Thermal Comfort \\
perception & (WBGT) & Urban Thermal Comfort \\
& & Universal Thermal Climate & Index (UTCI) \\
& & Luminance Curve System (LCS) & Basic Glare Comfort \\
& Visual Comfort & Unified Glare Rating (UGR) & Standard Index of Glare Comfort \\
& & DGP & Detailed Glare Comfort \\
\hline
\end{tabular}

\subsection{Visual Comfort-DGP}

DGP is a visual comfort assessment indicator that evaluates the likelihood of glare that can be caused by light sources in the vertical plane of a room. This visual comfort index is calculated based on the illuminance of the vertical plane, and the illuminance of 
the space where the light enters. Since the indicator recognizes a vertical plane as a light source, it is mainly used to investigate the possibility of indoor glare caused by natural light. DGP can be estimated more accurately than individual glare rating indicators, such as LCS or UGR, and Table 5 records the categories. However, despite the precision of the DGP, because natural light variation is irregular, the glare probability cannot be fully calculated. Therefore, there is an error in the calculated glare probability. Due to these limitations, the glare index is mainly used in the planning review phase, and in academic research. Overall, at the academic research level, DGP is recognized as the most common indicator for evaluating visual comfort $[14,17]$.

Table 5. Comfort criteria range of DGP and DGI.

\begin{tabular}{|c|c|c|c|c|c|c|c|}
\hline Index & $\begin{array}{l}\text { Sense of } \\
\text { Comfort }\end{array}$ & Range & Index & $\begin{array}{l}\text { Sense of } \\
\text { Comfort }\end{array}$ & Range & $\begin{array}{l}\text { Sense of } \\
\text { Comfort }\end{array}$ & Range \\
\hline \multirow{4}{*}{ DGP } & Imperceptible & $0.35>\mathrm{A}$ & \multirow{4}{*}{ DGI } & Just Perceptible & $16>\mathrm{A}$ & $\begin{array}{c}\text { Just } \\
\text { Uncomfortable }\end{array}$ & $24>A \geqq 22$ \\
\hline & Perceptible & $0.4>\mathrm{A} \geqq 0.35$ & & Noticeable & $18>A \geqq 16$ & Uncomfortable & $26>A \geqq 24$ \\
\hline & Disturbing & $0.45>\mathrm{A} \geqq 0.4$ & & Just Acceptable & $20>\mathrm{A} \geqq 18$ & Just Intolerable & $28>A \geqq 26$ \\
\hline & Intolerable & $\mathrm{A} \geqq 0 . \overline{4} 5$ & & Acceptable & $22>A \geqq 20$ & Intolerable & $\mathrm{A} \geqq \overline{28}$ \\
\hline
\end{tabular}

In Yun's research, DGP was used to evaluate the lighting performance and visual comfort of office space. The DGP for each sorted type was calculated according to the status of the louver, such as the length, size, and angle installed on the facade of office space. The optimal louver specification was suggested based on the calculated DGP [17].

Furthermore, Park created an algorithm that automatically selects the optimal facade by setting the DGP, illuminance, insolation amount, and type of louver as variables. The algorithm was designed to create a model by automatically selecting the optimized Wall Window Ratio (WWR), facade pattern, and the direction of the building based on the local sunshine environment conditions. The created algorithm could perform that assessment of visual comfort in the planning step [18].

As can be seen from the above studies, DGP is used as estimation tool that can determine visual comfort, in addition to determining glare in the indoor space [17-19]. The trend can be seen as the basis that DGP can be used as a visual comfort evaluation index. Therefore, DGP was selected in this study as a visual evaluation indicator.

\subsection{Tactile Comfort-PMV}

In general, tactile comfort is interpreted as thermal comfort in the field of architecture, because the thermal sensory experience is one of the tactile sensations that we can constantly feel indoors. Therefore, the evaluation indicator of thermal comfort was recognized as an index to assess tactile comfort. Accordingly, PMV was selected as an assessment index. PMV is a user-based comfort indicator suggested by ISO 7730, and it was produced based on thermal equilibrium. To calculate PMV, various indoor environmental indicators, such as dry-bulb temperature, relative humidity, mean radiant temperature, and wind speed, are demanded. Due to these characteristics, PMV has traditionally been used to evaluate the comfort of indoor spaces, and this recognition is also shown in previous studies [15]. The human body heat sensation according to the calculated PMV value is defined in Table 6 .

In Cheong's research, he conducted a study with the aim of finding a comfortable thermal environment condition in classroom spaces according to the presence or absence of humidification and ventilation in winter. After targeting a classroom space measuring $14 \mathrm{~m}$ wide, $8 \mathrm{~m}$ long, and $2.6 \mathrm{~m}$ high, the PMV was calculated by collecting indoor environment data for each quarter-point of width. Using the PMV calculated through a series of processes, the change in the comfort level of the classroom space was reviewed, and based on this, the appropriate relative humidity to maintain the thermal comfort of the classroom space was suggested [20]. 
Table 6. Comfort criteria range of PMV.

\begin{tabular}{|c|c|c|c|c|c|}
\hline \multirow{2}{*}{ Calculated PMV } & \multirow{2}{*}{ Sense of Comfort } & \multirow{2}{*}{ PPD } & \multicolumn{3}{|c|}{ Persons Predicted to Vote (\%) } \\
\hline & & & 0 & $-1,0$, or +1 & $-2,-1,0,+1$, or +2 \\
\hline+2 & Warm & 75 & 5 & 25 & 70 \\
\hline+1 & & 25 & 30 & 75 & 95 \\
\hline+0.5 & Slightly warm & 10 & 55 & 90 & 98 \\
\hline 0 & Natural & 5 & 60 & 95 & 100 \\
\hline-0.5 & Slightly & 10 & 55 & 90 & 98 \\
\hline-1 & Slightly cool & 25 & 30 & 75 & 95 \\
\hline-2 & Cool & 75 & 5 & 25 & 70 \\
\hline
\end{tabular}

Kang's research used PMV to understand the change in thermal environment that can occur when double-skin cladding is applied to office spaces in Seoul. As a result, it was concluded that during the spring season, the thermal comfort performance of office space with double skin was higher than that of the office space before installation. Through these research results, we proved the effectiveness of the double skin [21]. In addition, examples of PMV application studies are appearing in various fields, such as the production of automated facility-control algorithms using PMV fluctuations [22-25]. Therefore, it was determined that PMV was qualified to evaluate the thermal environment, and with the criteria presented in Table 6, the Hanok was set as an evaluation index to judge comfort.

\subsection{Selection of Comfort Index}

As a result of the review in the previous research stage, the necessity to directly apply the human sensory evaluation index to the Hanok comfort evaluation system was derived. For the research purpose, among the contents presented in KS A 6300, items that do not directly evaluate the user's sensory organs were classified, and as a result, the evaluation index in the tactile and visual fields was insufficient. To replace this, a literature review was performed, and PMV and DGP were finally selected as alternative evaluation indicators. The environmental factors for calculating them were judged to be able to secure data without damaging the space in the field as shown in Table 7. Therefore, for the purpose of this study to evaluate the comfort of Hanok, PMV and DGP were judged to be the most suitable evaluation indicators to be applied to the KS Hanok evaluation system.

Table 7. Evaluation indices of sensory comfort category.

\begin{tabular}{ccc}
\hline Sensory Comfort Category & Evaluation Index & Required Environmental Factors \\
\hline Visual Comfort & DGP & Illuminance \\
Luminance \\
\hline Tactile Comfort & & Dry-bulb Temperature \\
& & Mean Radiant Temperature \\
& PMV & Relative Humidity \\
Wind Speed \\
Clothing Level \\
\hline
\end{tabular}

\section{Designing a Plan for Collecting Hanok Indoor Environment and User Response Data}

\subsection{Review of the Data Collection Needs}

In the previous step, quantitative indicators to assess human sensory comfort were calculated. Finally, DGP and PMV were selected as evaluation indices, and each index was confirmed to have proper estimation criteria through the literature review.

However, it was difficult to find a research case that directly utilized quantitative indicators, such as DGP and PMV, in the Korean traditional building. This raised doubts as to whether the chosen indices could assess the Hanok's unique value. Therefore, it was 
necessary to check whether the assessment indices could correctly evaluate comfort for users. In addition, the method of verifying DGP and PMV needed to be confirmed through environmental and user response data simultaneously measured in the Hanok. If the user data and quantitative index that were measured at the same time showed the same result, the evaluation items would have significance. For this, under the concept drawn up in Figure 2, an environmental and user response data collection plan of the target building was designed [13].

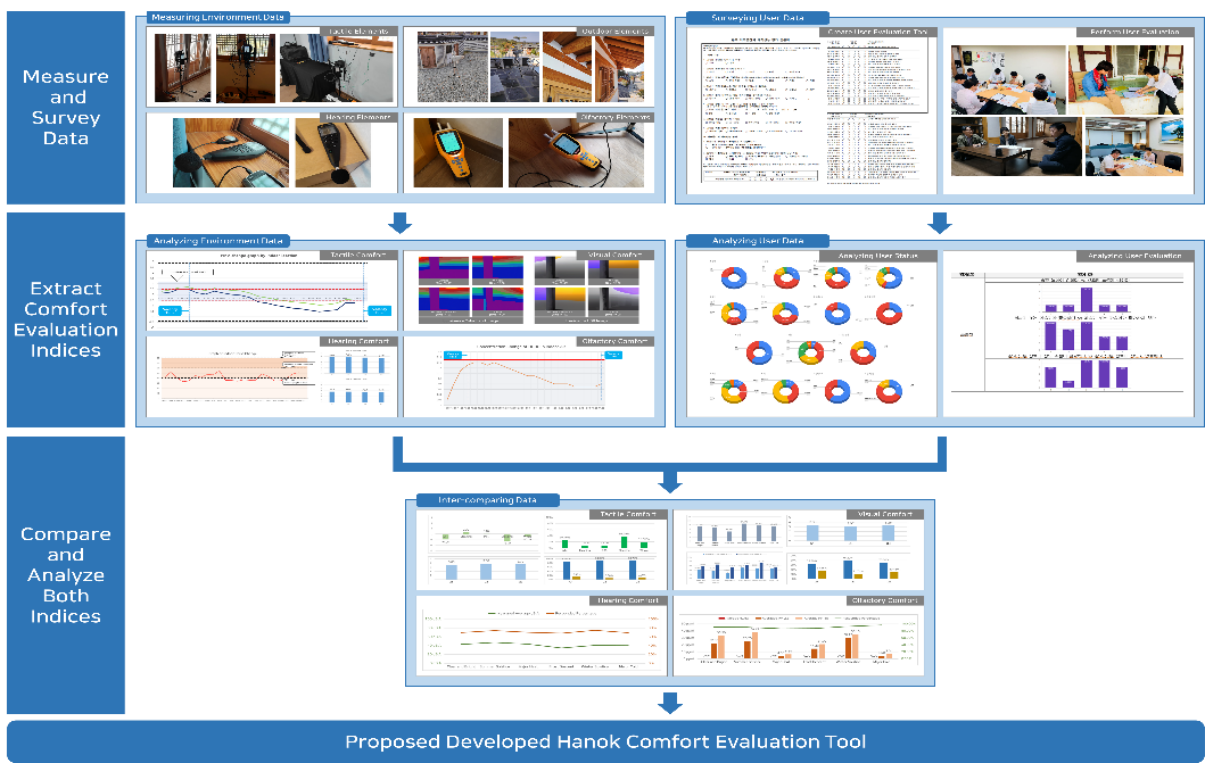

Figure 2. Designed plan for developing the comfort evaluation standard of Hanok.

\subsection{Investigating Method and Equipment, Tools}

The assessment index data collection of Hanok was designed by measuring the target building's environmental factors required for the calculation of DGP and PMV, and then calculating the value through a calculation program. The specific step of measuring is written in Table 8. PMV requires environmental and user data, such as dry-bulb temperature, relative humidity, mean radiant temperature, wind speed, clothing level, and metabolic rate. User variables had to be classified as control factors, because they were not related to spatial performance. Therefore, the clothing level and metabolic rate were set to 0.61 and 1.2, respectively, to control variables, and four environmental data were collected. The design time for environmental factors was set to $24 \mathrm{~h}$, and data were measured using Testo 480, which is a comprehensive environmental measuring device. All collected data were calculated in $1 \mathrm{~h}$ time steps using the PMV Calculator function of the Ladybug series, an environmental analysis plug-in of the Rhino Grasshopper program [26,27]. All of the program and equipment information used in the measuring plan is written in Table 9.

In principle, it is correct to calculate the DGP based on field data as well. However, it is impossible to control variables that cause light scattering, such as weather conditions, air quality, and type of user behavior. Therefore, DGP was calculated through simulation based on the 3D modeling of target sites. To perform more accurate simulation, 3D modeling of Hanok was produced by using detailed drawing, and physical property information of the target building was applied to 3D modeling. Afterwards, DGP of the target space was calculated using the Ladybug series used in PMV calculation [26]. Tables 10 and 11 list all of the environmental data collection methods and measuring equipment presented. 
Table 8. Investigation method of environmental factors.

\begin{tabular}{ccc}
\hline Property & Sensory Comfort Category & Step of Collecting Environmental Data \\
\hline Physical & Visual Comfort & $\begin{array}{c}\text { Create 3D modeling data by construction drawing } \\
\text { perception }\end{array}$ \\
\cline { 2 - 3 } & Tactile Comfort & $\begin{array}{c}\text { Check Hanok material data and put the material data into 3D modeling } \\
\text { Analyze DGP using Ladybug series }\end{array}$ \\
& $\begin{array}{c}\text { Extract essential environmental factors } \\
\text { by ASHRAE 55 and ISO 7730 analysis } \\
\text { Measure environmental factors using Testo 480 }\end{array}$ \\
\end{tabular}

Table 9. Program and equipment of the investigation method.

\begin{tabular}{|c|c|c|c|c|}
\hline Property & $\begin{array}{l}\text { Sensory Comfort } \\
\text { Category }\end{array}$ & & rogram and Equipment Status & \\
\hline \multirow[b]{2}{*}{$\begin{array}{l}\text { Physical } \\
\text { perception }\end{array}$} & Visual Comfort & $\begin{array}{l}\text { Program Name } \\
\text { Performable } \\
\text { Simulation }\end{array}$ & $\begin{array}{l}\text { Grasshopper Ladybug Series } \\
\text { Thermal Comfort Analysis } \\
\text { Overall Sunlight Analysis } \\
\text { Outdoor Environment Analysis }\end{array}$ & \\
\hline & Tactile Comfort & $\begin{array}{l}\text { Model Name } \\
\text { Measurement } \\
\text { factor } \\
\text { Installation Space } \\
\text { Install Location }\end{array}$ & $\begin{array}{c}\text { Testo } 480 \\
\text { Dry-bulb Temperature } \\
\text { Mean Radiant Temperature } \\
\text { Relative Humidity } \\
\text { Wind Speed } \\
\text { Living Room } \\
\text { In front of Opening }\end{array}$ & \\
\hline
\end{tabular}

Table 10. Comparing Temperature and Relative Humidity data between Gang-neung and Hwa-sun.

Season Temperature $\left({ }^{\circ} \mathbf{C}\right) \quad$ Relative Humidity (\%)


Table 11. Architectural and structural outline of the analysis target.

\begin{tabular}{|c|c|c|c|}
\hline Target & & tline & Photo and Building Plan \\
\hline \multirow{9}{*}{$\begin{array}{l}\text { Ojuk Hanok } \\
\text { Village }\end{array}$} & Site Area & $12,300 \mathrm{~m}^{2}$ & \\
\hline & Total Floor Area & $1318.5 \mathrm{~m}^{2}$ & \\
\hline & Building Area & $1418.94 \mathrm{~m}^{2}$ & \\
\hline & Principal Use & Accommodation & \\
\hline & Structure & Wooden Post \& Beam Structure & \\
\hline & Location & Gang-neung & \\
\hline & Target Space & Living & \\
\hline & Target Area & $14.4 \mathrm{~m}^{2}$ & \\
\hline & Window Wall Ratio & $17.58 \%$ & \\
\hline \multirow{9}{*}{$\begin{array}{l}\text { Hwa-sun } \\
\text { Hanok }\end{array}$} & Site Area & $540 \mathrm{~m}^{2}$ & \multirow{9}{*}{ 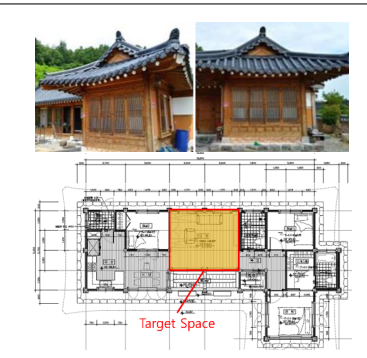 } \\
\hline & Total Floor Area & $99.586 \mathrm{~m}^{2}$ & \\
\hline & Building Area & $99.586 \mathrm{~m}^{2}$ & \\
\hline & Principal Use & Residence & \\
\hline & Structure & Wood Post \& Lintel Structure & \\
\hline & Location & Hwa-sun & \\
\hline & Target Space & Living & \\
\hline & Target Area & $17.76 \mathrm{~m}^{2}$ & \\
\hline & Window Wall Ratio & $19.33 \%$ & \\
\hline
\end{tabular}

For the collection of user data, the user evaluation system used in Lee's research was applied [13]. User data were collected for nine months from April 2019 to January 2020, and environmental factors were also measured. User comfort was evaluated by answering three questions shown below in Figure 3. The assessment subject was the Hanok user, and each question had a different intention. Q1 determined whether the user felt uncomfortable about a specific stimulus felt indoors. Q2 asked if there was a need to take action to prevent irritation indoors. Q3 compared the user's residence and the current place. For the purposes of this study, Q3 had no utility value. Therefore, user data were collected around Q1 and Q2 items [13].

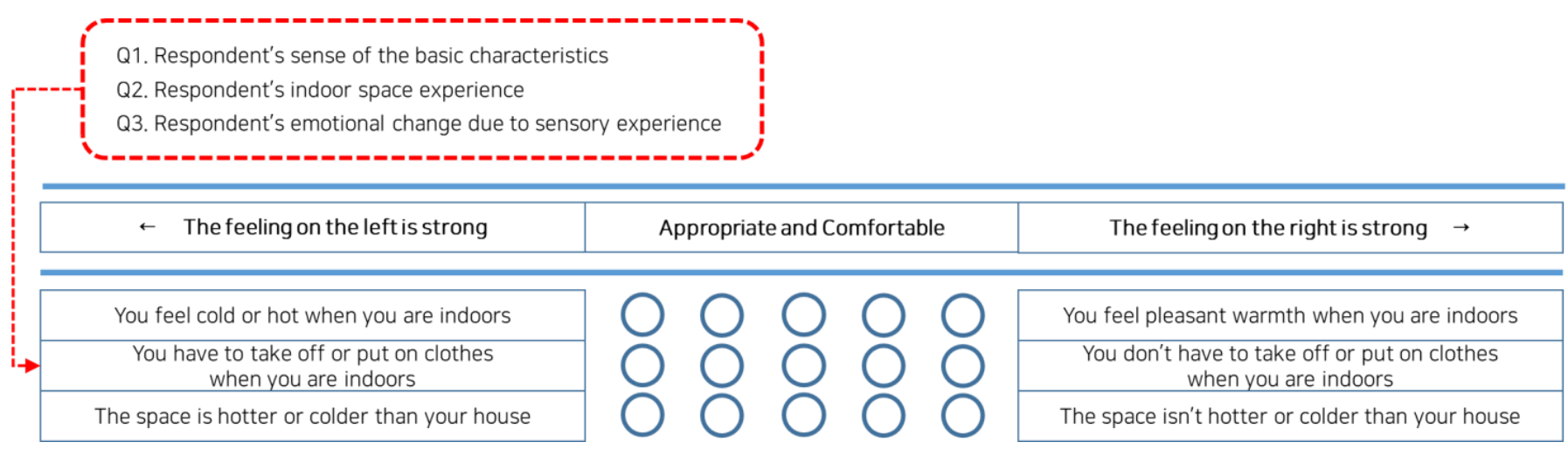

Figure 3. Part of the user evaluation tool.

\subsection{Selection of Investigating Place}

The location of sites was also selected from among the 29 Korean traditional buildings mentioned in Lee's study [13]. These sites are scattered across Korea, including Seoul, Gyeong-gi, Gang-won, and Jeon-nam provinces. These Hanok are mainly used for public and residential purposes. In order to evaluate the Hanok more precisely, the user needed to have been staying at the target site for a long time, and performing everyday life activities. Therefore, the location was set for Hanok that were used for residential purposes. As a result of selecting location according to the set conditions, targets were finally selected in Gang-neung and Hwa-sun [13]. 
However, although the two selected locations are classified as similar climatic zones according to legal standards, there may be differences in micro-environmental aspects. Therefore, it was necessary to determine whether the climates of the two regions showed similar trends at any given point in time. Based on that premise, the changes in temperature and humidity of the two sites were compared by season. As a result, it was found that the two regions had similar climatic conditions, as shown in the graph in Table 10. Based on the result of Table 10, the final analysis target site was selected as shown in Table 11. Two selected buildings were built for the purpose of residence, and had various commonalities in terms of spatial planning, such as the way of entering the interior space, the relationship between the interior and the exterior, the area of the opening, and the elevation of the space to be analyzed. The spatial information on the selected buildings is presented in Table 11.

The Gang-neung site was built by mixing wooden and reinforced-concrete structure. This is generally applied in modern Hanok. This aimed to complement the weak environmental performance of wooden structure, and simultaneously express the advantages of vernacular building. On the other hand, the Hwa-sun site was built in only traditional wooden structure. Therefore, the selected building had weaknesses in terms of thermal environment. The reason why the structure of the building to be evaluated was not set identically was to check whether PMV could detect the difference in thermal environment according to the building structure. The verification method was performed as a process of comparing whether the feeling of comfort according to the evaluation criteria of PMV was the same as the attribute of the user evaluation result. The construction method of the selected space is presented in Table 11.

\subsection{Planning Investigation Schedule}

Typically, environmental data should be collected simultaneously in all regions. However, due to real-life problems, such as manpower and equipment, it was impossible to simultaneously collect data from all regions. To overcome this limitation, data were collected by setting a temporal category in which seasonal characteristics were expressed. The 24 seasonal days were the traditional seasonal indicators of the Korean Peninsula, and the climate characteristics of each point were clear. However, it was also difficult to measure data at the same time at all seasonal points.

Therefore, six points of the most characteristic time based on the 24 seasons were derived, and the measuring schedule was planned. Table 12 below shows the four days selected. Based on these, the evaluation schedule as shown in Figure 4 was finally drawn up by setting one week before and after each of the six points as the period in which the seasonal characteristics were maintained [13].

Table 12. Climate characteristics by selected date.

\begin{tabular}{cccc}
\hline Name & Date & Relative Humidity (\%) & Measured Date \\
\hline Clear and Bright & 4 April-5 April & The weather is sunny and good & 4 April-13 April \\
Summer Solstice & 21 June-22 June & The length of day is the longest & 13 June-2 July \\
Major Heat & 22 July-23 July & The hottest day & 12 August-19 August \\
Frost Descent & 23 October-24 October & The frostiest day & 17 October-5 November \\
Winter Solstice & 21 December-22 December & The length of day is the shortest & 18 December-25 December \\
Major Cold & 20 January-21 January & The coldest day & 15 January-22 January \\
\hline
\end{tabular}

A data collection plan, including data collection method, measurement equipment, location, and schedule, was developed to compare the comfort evaluation index and user evaluation. Data were collected according to the written plan, and the collection period was carried out for nine months from April 2019 to January 2020. All data were organized in graph and table format, as shown in Figures 5 and 6, by measurement time-point. 


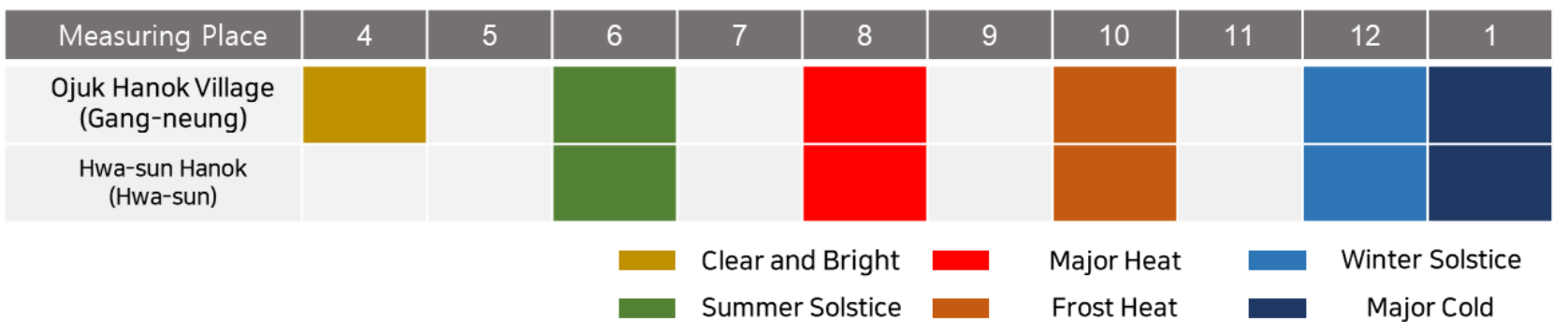

Figure 4. The schedule of investigating environmental and user data.

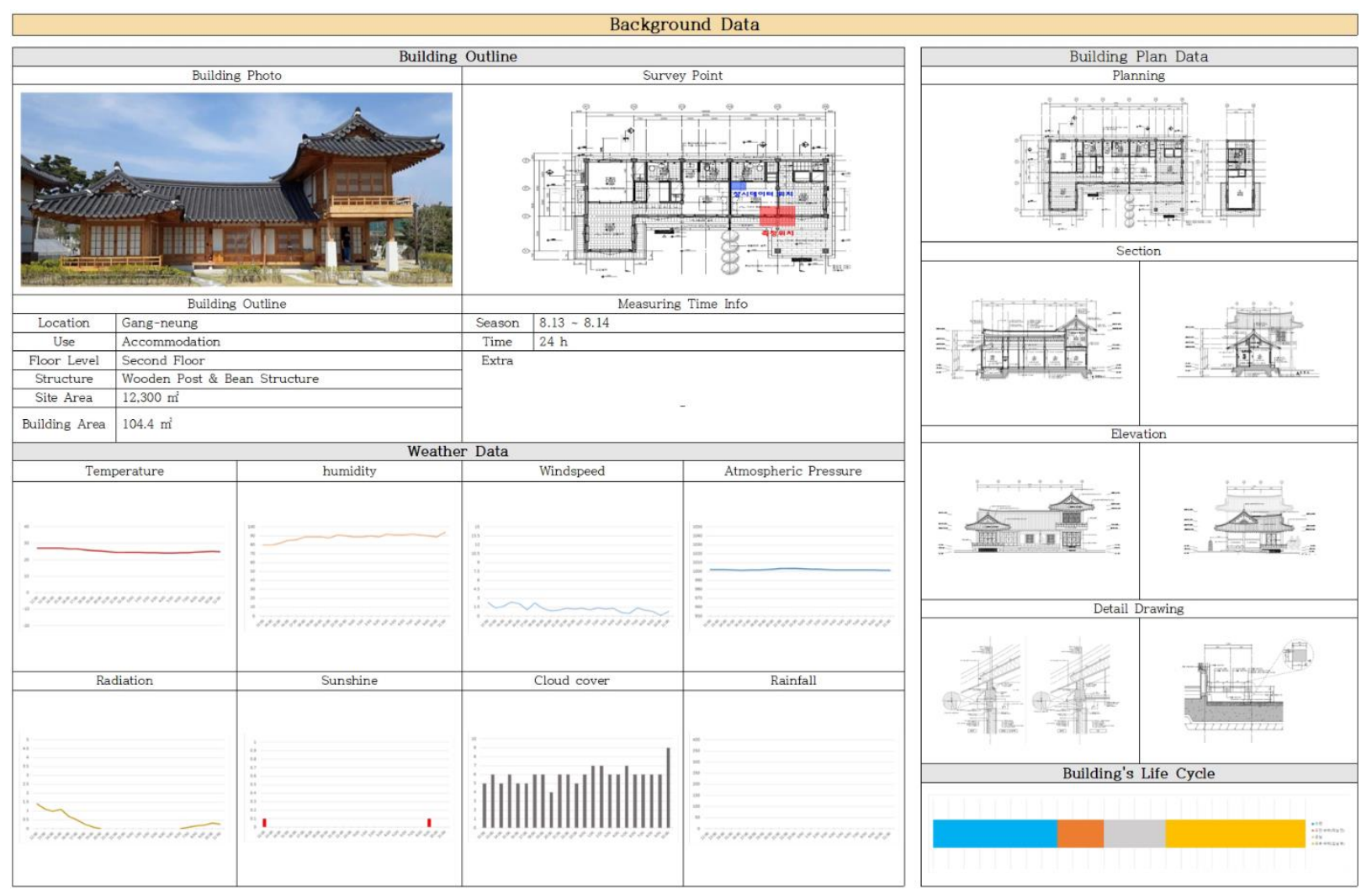

Figure 5. Part of measuring data sheet with building outline and measuring time information. 


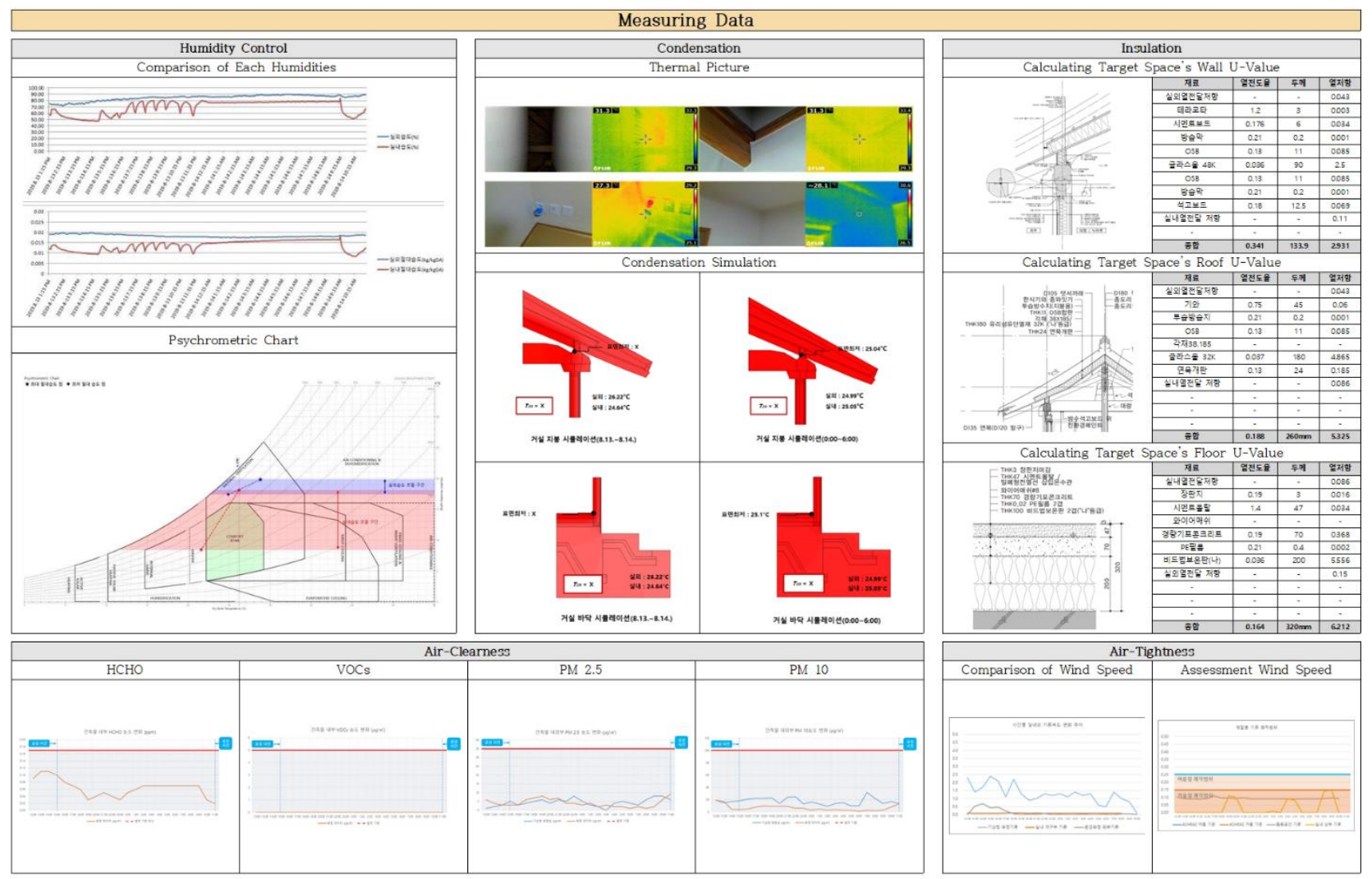

Figure 6. Part of measuring data sheet with environmental data.

\section{Analyzing the Environmental and User Data}

\subsection{Spatial Analysis Based on the Collected Comfort Index Data}

Using the collected data, the PMV and DGP of the target spaces were calculated for each measurement point. The calculated evaluation index was compared with the user evaluation data prepared at the same time-point. Comparative analysis was used to confirm whether the calculated data of the evaluation index were similar to the assessment results of actual Hanok users. The analysis results confirmed that the comfort indices could be used in the KS system.

For comparative analysis, the average value of PMV and DGP data collected on an hourly basis for $24 \mathrm{~h}$ was calculated. PPD is the expected average response rate of users to the calculated PMV, and it means the positive response rate regarding the user's comfort that is derived together when the PMV is calculated [28-30]. In addition, the numerical meaning of the DGP coefficient means the probability of glare that can be felt in the human visual organ [31,32]. Therefore, PMV and DGP could be substituted with the PPD and the probability of feeling glare, respectively. Thus, the two indicators were converted into the aforementioned indices for comparison with the user assessment and comparison was performed.

User evaluation data were also converted into satisfaction and dissatisfaction rates, and evaluated. In the case of tactile comfort, a lower score indicated that it was cold or hot, while a higher score indicated that the building had an appropriate thermal environment. Therefore, the dissatisfaction rate was calculated by using the number of one-point or twopoint responses that could clearly grasp that the Hanok felt unpleasant. In the evaluation of visual comfort, it was interpreted that the higher the score, the stronger the glare caused by natural light that was felt. Therefore, the glare also calculated the probability of feeling glare based on the number of assessors of 4 or 5 points.

The comparative analysis was performed in the order of Gang-neung and Hwa-sun, and the trend of fluctuations at all measurement points was also analyzed. After that, the 
differences between the evaluation indicators derived from the two regions and user data were analyzed.

\subsection{Visual Comfort Data}

The DGP of the Gang-neung site by measured time-point was distributed in the $0.003-0.330$ category, as shown in Table 13. If visual comfort evaluation was performed only on the DGP criteria, all calculated DGP were less than 0.350 . Therefore, they belonged to Imperceptible, and this site was classified as a place that does not cause visual discomfort of the users.

Table 13. Calculated DGP in the Gang-neung Hanok.

\begin{tabular}{|c|c|c|c|c|c|c|c|}
\hline \multirow{2}{*}{\multicolumn{2}{|c|}{ Category }} & \multicolumn{6}{|c|}{ Season } \\
\hline & & Clear and & Summer & Major & Frost & Winter & Major \\
\hline \multirow{4}{*}{ Time } & Sunrise & 0.030 & 0.005 & 0.003 & 0.180 & 0.230 & 0.003 \\
\hline & Noon & 0.290 & 0.260 & 0.270 & 0.300 & 0.320 & 0.310 \\
\hline & Max Solar & 0.300 & 0.270 & 0.260 & 0.310 & 0.330 & 0.330 \\
\hline & Sunset & 0.200 & 0.240 & 0.020 & 0.220 & 0.040 & 0.330 \\
\hline \multicolumn{2}{|c|}{ Average } & 0.205 & 0.193 & 0.138 & 0.252 & 0.230 & 0.243 \\
\hline \multicolumn{2}{|c|}{$\begin{array}{l}\text { A Sense of } \\
\text { Comfort }\end{array}$} & Imperceptible & Imperceptible & Imperceptible & Imperceptible & Imperceptible & Imperceptible \\
\hline
\end{tabular}

However, when the calculated result in Table 14 was substituted by the probability of occurrence of glare, up to $33 \%$ of users may have felt the glare. When converting the DGP for each time-point, the result was that, on average, 13.8 to $25.2 \%$ of people could feel glare. Accordingly, the response rate of dazzling natural light in user data was found to be $32.76 \%$ on average, and it showed a trend of increasing up to $44.26 \%$. In addition, the response rate of requiring shading elements, such as curtains and blinds, due to glare was $26.82 \%$ on average, and $81.87 \%$ of the proportion of dissatisfied users in Q1 requested shading elements. Compared to the maximum DGP of 0.330 calculated by the Gang-neung Hanok, more than $10 \%$ of users answered that the indoor space was dazzling.

Table 14. Percentage of respondents for visual comfort in the Gang-neung Hanok.

\begin{tabular}{ccccccccc}
\hline & $\begin{array}{c}\text { Response } \\
\text { Type }\end{array}$ & $\begin{array}{c}\text { Clear and } \\
\text { Bright }\end{array}$ & $\begin{array}{c}\text { Summer } \\
\text { Solstice }\end{array}$ & $\begin{array}{c}\text { Major } \\
\text { Heat }\end{array}$ & $\begin{array}{c}\text { Season } \\
\text { Frost } \\
\text { Descent }\end{array}$ & $\begin{array}{c}\text { Winter } \\
\text { Solstice }\end{array}$ & $\begin{array}{c}\text { Major } \\
\text { Cold }\end{array}$ & $\begin{array}{c}\text { Average } \\
\text { Q1 }\end{array}$ \\
& Comfort & $65.89 \%$ & $66.22 \%$ & $72.73 \%$ & $66.67 \%$ & $55.74 \%$ & $76.19 \%$ & $67.24 \%$ \\
& Dazzling & $34.11 \%$ & $33.78 \%$ & $27.27 \%$ & $33.33 \%$ & $44.26 \%$ & $23.81 \%$ & $32.76 \%$ \\
\hline \multirow{2}{*}{ Q2 } & Not Required & $78.29 \%$ & $74.32 \%$ & $67.27 \%$ & $77.27 \%$ & $70.49 \%$ & $71.43 \%$ & $73.18 \%$ \\
& Need a Curtain & $21.71 \%$ & $25.68 \%$ & $32.73 \%$ & $22.73 \%$ & $29.51 \%$ & $28.57 \%$ & $26.82 \%$ \\
\hline
\end{tabular}

Hwa-sun's DGP in Table 15 ranged from 0.003 to 0.310. It also showed a DGP value of less than 0.350 , so it was assessed as an imperceptible environment. The average DGP for each time-point of the target was $0.140-0.218$, indicating that $14-21.2 \%$ of all users could feel glare at the Hwa-sun Hanok. From the DGP analysis results alone, it could be evaluated that this analysis target had relatively less glare than Gang-neung.

However, as shown in Table 16, Hwa-sun also showed a similar proportion to Gangneung, with an average of $33.5 \%$ of users who felt glare, and showed a trend of up to $46.67 \%$ at each point in time. In addition, the percentage of users who requested the shading element due to glare was $17.92 \%$ on average, and $53.48 \%$ of the rate of dissatisfaction with the glare showed that they required the shading element. It also indicated that the indoor space was dazzling, compared to the calculated maximum DGP of 0.310 . 
Table 15. Calculated DGP in the Hwa-sun Hanok.

\begin{tabular}{|c|c|c|c|c|c|c|c|}
\hline \multirow{2}{*}{\multicolumn{2}{|c|}{ Category }} & \multirow{2}{*}{$\begin{array}{c}\text { Clear and } \\
\text { Bright }\end{array}$} & \multicolumn{4}{|c|}{ Season } & \multirow{2}{*}{$\begin{array}{c}\text { Major } \\
\text { Cold }\end{array}$} \\
\hline & & & Summer & Major & Frost & Winter & \\
\hline \multirow{4}{*}{ Time } & Sunrise & 0.003 & 0.05 & 0.01 & 0.06 & 0.04 & 0.03 \\
\hline & Noon & 0.28 & 0.26 & 0.27 & 0.28 & 0.28 & 0.27 \\
\hline & Max Solar & 0.28 & 0.27 & 0.27 & 0.29 & 0.29 & 0.3 \\
\hline & Sunset & 0.05 & 0.07 & 0.01 & 0.24 & 0.1 & 0.24 \\
\hline \multicolumn{2}{|c|}{ Average } & 0.205 & 0.15325 & 0.1625 & 0.14 & 0.2175 & 0.1775 \\
\hline \multicolumn{2}{|c|}{$\begin{array}{l}\text { A Sense of } \\
\text { Comfort }\end{array}$} & Imperceptible & Imperceptible & Imperceptible & Imperceptible & Imperceptible & Imperceptible \\
\hline
\end{tabular}

Table 16. Percentage of respondents for visual comfort in the Hwa-sun Hanok.

\begin{tabular}{ccccccccc}
\hline & $\begin{array}{c}\text { Response } \\
\text { Type }\end{array}$ & $\begin{array}{c}\text { Clear and } \\
\text { Bright }\end{array}$ & $\begin{array}{c}\text { Summer } \\
\text { Solstice }\end{array}$ & $\begin{array}{c}\text { Major } \\
\text { Heat }\end{array}$ & $\begin{array}{c}\text { Season } \\
\text { Frost } \\
\text { Descent }\end{array}$ & $\begin{array}{c}\text { Winter } \\
\text { Solstice }\end{array}$ & $\begin{array}{c}\text { Major } \\
\text { Cold }\end{array}$ & $\begin{array}{c}\text { Average } \\
\text { Q1 }\end{array}$ \\
& Comfort & - & $56.25 \%$ & $53.33 \%$ & $66.67 \%$ & $75.00 \%$ & $81.25 \%$ & $66.50 \%$ \\
& Dazzling & - & $43.75 \%$ & $46.67 \%$ & $33.33 \%$ & $25.00 \%$ & $18.75 \%$ & $33.50 \%$ \\
\hline \multirow{2}{*}{ Q2 } & Not Required & - & $68.75 \%$ & $80.00 \%$ & $86.67 \%$ & $75.00 \%$ & $100.00 \%$ & $82.08 \%$ \\
& Need a Curtain & - & $31.25 \%$ & $20.00 \%$ & $13.33 \%$ & $25.00 \%$ & $0.00 \%$ & $17.92 \%$ \\
\hline
\end{tabular}

\subsection{Comparing the Change Trend of Visual Assessment Indices}

As shown in Figure 7, The change trend of DGP in the Gang-neung target showed the average DGP for each time-point and the dissatisfaction rate for the glare of Q1 and Q2. The season with the least difference between the two data was major cold, and the value stayed at $1.87 \%$. On the other hand, at the time of major heat, which was the summer period, the difference between the two values was $16.18 \%$, which showed the greatest difference. The average difference between the data at each time-point was $8.74 \%$, indicating that the DGP had an error of $8.7 \%$ in the dissatisfaction rate felt by real users. As the season changed, these phenomena could increase by up to $16 \%$. Considering these results, to utilize DGP in the KS standard, it was necessary to adjust the error.

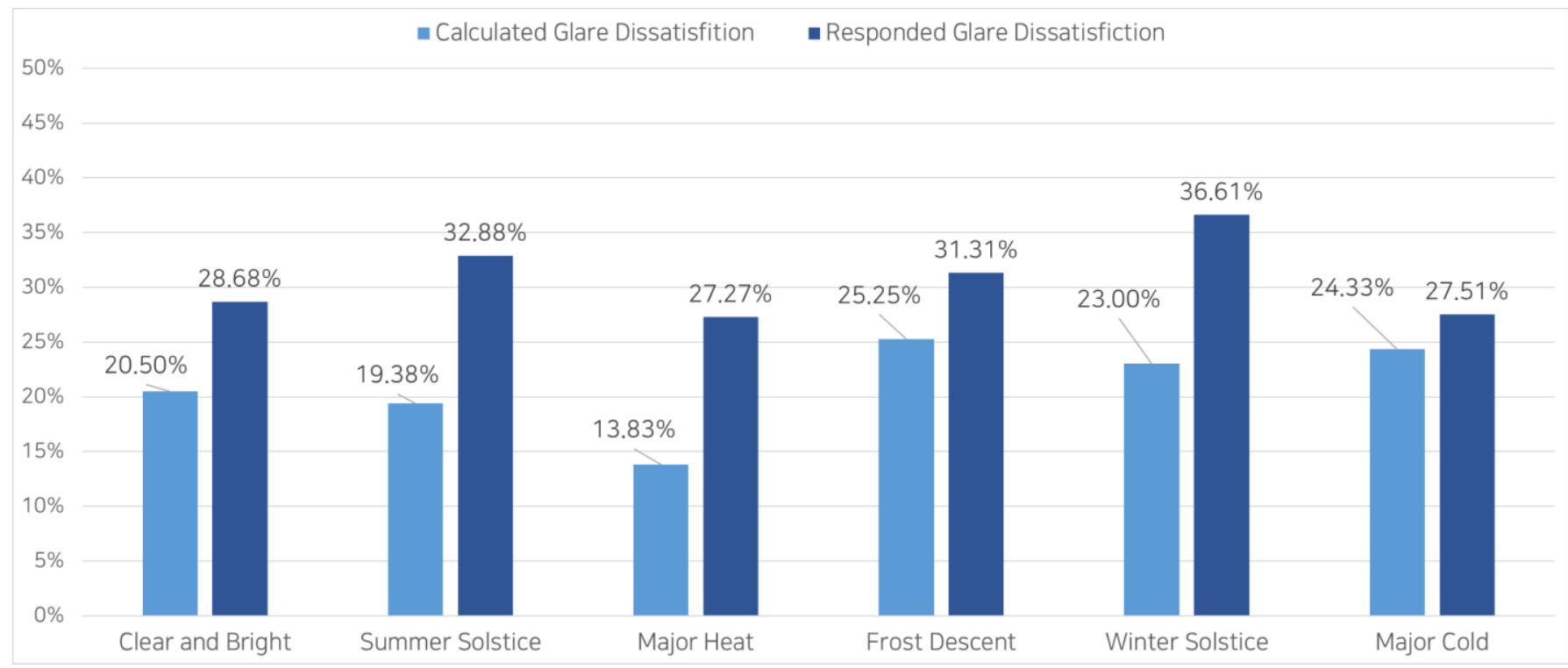

Figure 7. Comparison of the user response data and DGP in the Gang-neung Hanok. 
In addition, the change of DGP in Hwa-sun showed an average difference of $7.56 \%$ between DGP and the user response data as presented by Figure 8 . The season with the least difference between the two data was frost descent, which showed a difference of $1.58 \%$. On the other hand, the difference in dissatisfaction rate at the time of the summer solstice was $21.25 \%$, showing the largest difference including Gang-neung and Hwa-sun. The characteristic part was the difference between the value of DGP calculated at the time of major cold, and the user's glare dissatisfaction rate. Despite the DGP being 0.210, the user's glare response rate was $9.38 \%$, while the DGP was measured to be $11.63 \%$ higher. The glare probability according to DGP for the Hwa-sun Hanok was also calculated to be $7.56 \%$ lower on average, and there could have been a difference in glare probability of up to $21 \%$.

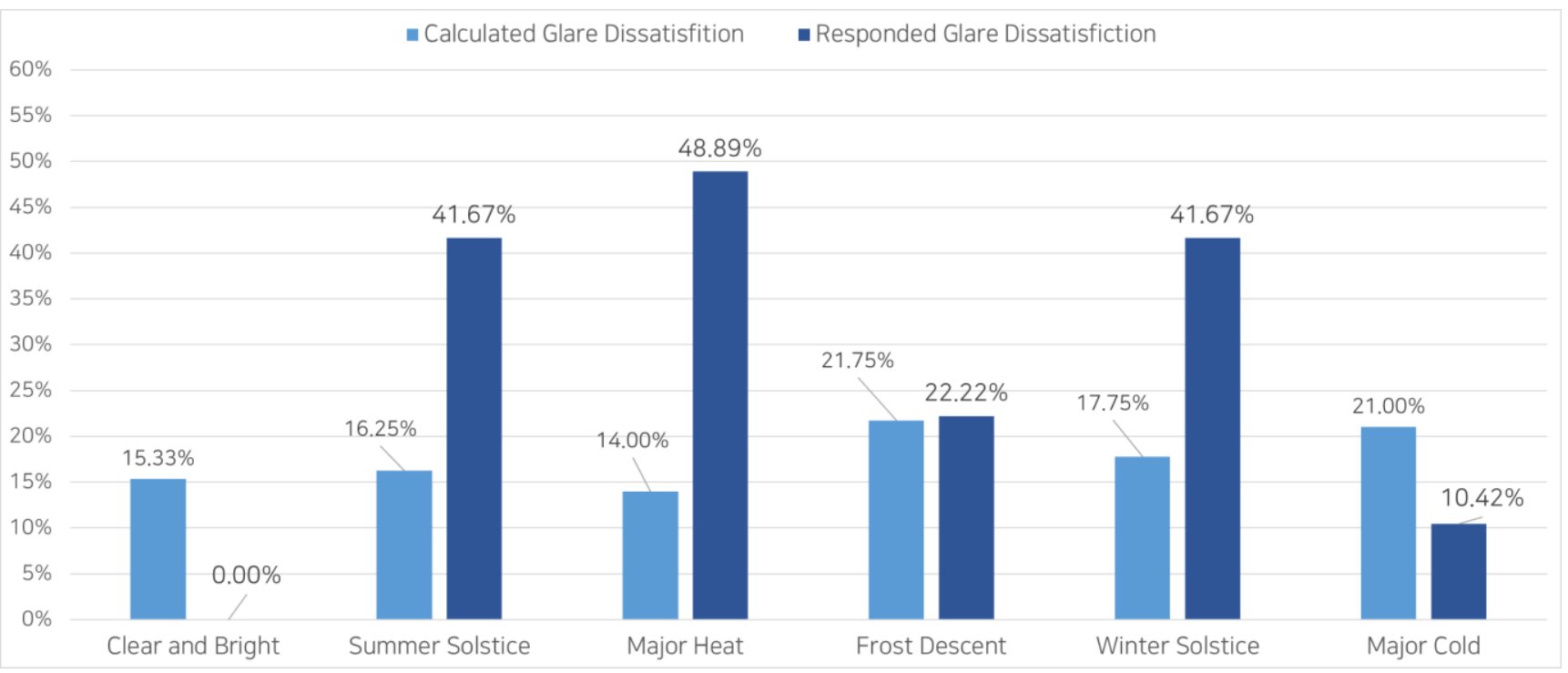

Figure 8. Comparison of user response data and DGP in the Hwa-sun Hanok.

Through the results of the two regions' analyses, it was found that DGP showed a certain difference from actual user comfort, regardless of the region conditions. The result was due to the comparative analysis that users of Gang-neung and Hwa-sun could feel glare with 8.41 and $7.56 \%$ higher probability than the calculated DGP, respectively. This means that to evaluate the visual comfort of the building through DGP, it was necessary to review the contents that could correct the error rate of $7-8 \%$.

\subsection{Tactile Comfort Data}

The calculated PMV of the Gang-neung Hanok was distributed within the range $-1.51-0.51$, and the hourly average PMV can be checked through Table 17 . The lowest value, -1.51 , appeared in the morning hours at the time of frost descent, and according to the criteria of PMV, it was analyzed as an environment of slightly cold. The PPD at that point was $51.69 \%$, which means that about half of the users might have been dissatisfied with the thermal comfort at that point. In contrast, it was found that the time of calculation of the highest value of 0.51 was the cleaning and maintenance time of the summer solstice, and the corresponding section was classified as a slightly warm area. Furthermore, the PPD was $10.97 \%$, indicating that about $10 \%$ of all users might have complained about thermal comfort. The average PMV at each time-point ranged -1.02 to 0.24 . Based on the above result, the Gang-neung site was classified as a space where the user could feel cold more easily than heat. Furthermore, a maximum of 30 users might feel uncomfortable in the Gang-neung building. However, the percentage of users presented in Table 18 who actually felt hot or cold in the indoor space ranged 2.7 to $12.4 \%$, with an average of $7.13 \%$ of users showing discomfort. As a result, the percentage of users who required supplemental 
thermal comfort in indoor spaces was revealed to be $4.31 \%$ on average. The result was 4 to $18 \%$ lower than the calculated PPD.

Table 17. Calculated PMV and PPD in the Gang-neung Hanok (PPD: \%).

\begin{tabular}{|c|c|c|c|c|c|c|c|c|c|c|c|c|c|}
\hline \multirow{3}{*}{\multicolumn{2}{|c|}{ Time }} & \multicolumn{12}{|c|}{ Seasons } \\
\hline & & \multicolumn{2}{|c|}{$\begin{array}{c}\text { Clear and } \\
\text { Bright }\end{array}$} & \multicolumn{2}{|c|}{$\begin{array}{l}\text { Summer } \\
\text { Solstice }\end{array}$} & \multicolumn{2}{|c|}{$\begin{array}{l}\text { Major } \\
\text { Heat }\end{array}$} & \multicolumn{2}{|c|}{$\begin{array}{c}\text { Frost } \\
\text { Descent }\end{array}$} & \multicolumn{2}{|c|}{$\begin{array}{l}\text { Winter } \\
\text { Solstice }\end{array}$} & \multicolumn{2}{|c|}{$\begin{array}{l}\text { Major } \\
\text { Cold }\end{array}$} \\
\hline & & PMV & PPD & PMV & PPD & PMV & PPD & PMV & PPD & PMV & PPD & PMV & PPD \\
\hline \multirow{4}{*}{ Time } & A.M. & -0.95 & 25.45 & -0.36 & 10.97 & -0.16 & 6.62 & -1.51 & 51.69 & -0.88 & 21.32 & -0.05 & 5.13 \\
\hline & Cleaning & 0.30 & 7.39 & 0.51 & 10.43 & 0.40 & 9.34 & -0.81 & 24.81 & -0.48 & 10.07 & 0.22 & 6.05 \\
\hline & P.M. & 0.04 & 7.12 & 0.18 & 8.77 & 0.10 & 5.66 & -0.63 & 14.60 & -1.28 & 39.39 & -0.21 & 8.00 \\
\hline & Sleeping & -1.22 & 36.95 & -0.58 & 12.97 & 0.48 & 9.81 & -1.31 & 41.37 & -1.07 & 29.12 & -0.19 & 6.52 \\
\hline \multicolumn{2}{|c|}{ Average } & -0.49 & 19.92 & -0.09 & 10.63 & 0.24 & 7.71 & -1.02 & 30.40 & -1.02 & 28.40 & -0.12 & 6.79 \\
\hline \multicolumn{2}{|c|}{$\begin{array}{l}\text { A Sense of } \\
\text { Comfort }\end{array}$} & \multicolumn{2}{|c|}{ Natural } & \multicolumn{2}{|c|}{ Natural } & \multicolumn{2}{|c|}{ Natural } & \multicolumn{2}{|c|}{ Slightly Cold } & \multicolumn{2}{|c|}{ Slightly Cold } & \multicolumn{2}{|c|}{ Natural } \\
\hline
\end{tabular}

Table 18. Percentage of respondents for tactile comfort in the Gang-neung Hanok.

\begin{tabular}{ccccccccc}
\hline & $\begin{array}{c}\text { Response } \\
\text { Type }\end{array}$ & $\begin{array}{c}\text { Clear and } \\
\text { Bright }\end{array}$ & $\begin{array}{c}\text { Summer } \\
\text { Solstice }\end{array}$ & $\begin{array}{c}\text { Major } \\
\text { Heat }\end{array}$ & $\begin{array}{c}\text { Season } \\
\text { Frost } \\
\text { Descent }\end{array}$ & $\begin{array}{c}\text { Winter } \\
\text { Solstice }\end{array}$ & $\begin{array}{c}\text { Major } \\
\text { Cold }\end{array}$ & $\begin{array}{c}\text { Average } \\
\text { Q1 }\end{array}$ \\
& Comfort & $87.60 \%$ & $97.30 \%$ & $94.55 \%$ & $95.45 \%$ & $93.44 \%$ & $88.89 \%$ & $92.87 \%$ \\
& Cold or Hot & $12.40 \%$ & $2.70 \%$ & $5.45 \%$ & $4.55 \%$ & $6.56 \%$ & $11.11 \%$ & $7.13 \%$ \\
\hline \multirow{2}{*}{ Q2 } & Not Required & $93.02 \%$ & $98.63 \%$ & $98.18 \%$ & $93.94 \%$ & $96.72 \%$ & $93.65 \%$ & $95.69 \%$ \\
& Need Clothes & $6.98 \%$ & $1.37 \%$ & $1.82 \%$ & $6.06 \%$ & $3.28 \%$ & $6.35 \%$ & $4.31 \%$ \\
\hline
\end{tabular}

On the other hand, Hwa-sun's PMV range was -1.69-2.15 as shown in Table 19, and it is evident that the fluctuation range was wider than that of Gang-neung. The minimum PMV was -1.60 at the cleaning and maintenance time at the time of major cold, and the heat sensation at that time was 'Cold'. The PPD at that time was $61.00 \%$, and six out of 10 users could complain of discomfort in the thermal environment. In contrast, the time when PMV was highest was the cleaning and maintenance time of the major heat season, and PMV recorded 2.15. The average value for each season was distributed over the range -1.5 to 1.58 , and it was found that the Hanok's thermal barrier performance was lower than that of Gang-neung. At this time, the category of PPD was $5.48-54.03 \%$, and it is evident that up to $54 \%$ of users felt dissatisfied with the thermal environment. In fact, the Gang-neung target had a reinforced concrete structure, but the target of Hwa-sun was built only with a wooden structure. Table 20 shows the accumulated phenomena, and the residents of the selected site had a higher dissatisfaction rate than the calculated data. The percentage of dissatisfaction with the thermal environment of the indoor space was calculated from 26.67 to $56.25 \%$ at each time-point. In addition, the user dissatisfaction rate was higher than that of PPD at all evaluation points. When comparing the two sites, the difference in the dissatisfaction rate was between 23.97 and $43.85 \%$. Derivation of these results can be evaluated as a situation where, despite similar climatic conditions, the indoor environment of the Hwa-sun Hanok was weaker than that of Gang-neung. 
Table 19. Calculated PMV and PPD in the Hwa-sun Hanok (PPD: \%).

\begin{tabular}{|c|c|c|c|c|c|c|c|c|c|c|c|c|c|}
\hline \multirow{3}{*}{\multicolumn{2}{|c|}{ Time }} & \multicolumn{12}{|c|}{ Seasons } \\
\hline & & \multicolumn{2}{|c|}{$\begin{array}{c}\text { Clear and } \\
\text { Bright }\end{array}$} & \multicolumn{2}{|c|}{$\begin{array}{l}\text { Summer } \\
\text { Solstice }\end{array}$} & \multicolumn{2}{|c|}{$\begin{array}{l}\text { Major } \\
\text { Heat }\end{array}$} & \multicolumn{2}{|c|}{$\begin{array}{c}\text { Frost } \\
\text { Descent }\end{array}$} & \multicolumn{2}{|c|}{$\begin{array}{l}\text { Winter } \\
\text { Solstice }\end{array}$} & \multicolumn{2}{|c|}{$\begin{array}{l}\text { Major } \\
\text { Cold }\end{array}$} \\
\hline & & PMV & PPD & PMV & PPD & PMV & PPD & PMV & PPD & PMV & PPD & PMV & PPD \\
\hline \multirow{4}{*}{ Time } & A.M. & - & - & 0.46 & 10.17 & 1.92 & 72.89 & 0.10 & 5.20 & -1.34 & 42.53 & -1.64 & 58.76 \\
\hline & Cleaning & - & - & 0.85 & 20.23 & 2.15 & 82.00 & 0.08 & 5.58 & -1.23 & 36.83 & -1.69 & 61.00 \\
\hline & P.M. & - & - & 0.70 & 17.03 & 1.51 & 50.15 & 0.20 & 5.82 & -0.79 & 18.18 & -1.41 & 46.27 \\
\hline & Sleeping & - & - & 0.10 & 5.30 & 1.23 & 36.96 & 0.09 & 5.16 & -1.09 & 30.44 & -1.46 & 48.89 \\
\hline \multicolumn{2}{|c|}{ Average } & - & - & 0.55 & 14.42 & 1.58 & 54.03 & 0.12 & 5.48 & -1.05 & 29.09 & -1.50 & 50.90 \\
\hline \multicolumn{2}{|c|}{$\begin{array}{l}\text { A Sense of } \\
\text { Comfort }\end{array}$} & \multicolumn{2}{|c|}{-} & \multicolumn{2}{|c|}{ Slightly Hot } & \multicolumn{2}{|c|}{ Hot } & \multicolumn{2}{|c|}{ Natural } & \multicolumn{2}{|c|}{ Slightly Cold } & \multicolumn{2}{|c|}{ Cold } \\
\hline
\end{tabular}

Table 20. Percentage of respondents for tactile comfort in the Hwa-sun Hanok.

\begin{tabular}{ccccccccc}
\hline & $\begin{array}{c}\text { Response } \\
\text { Type }\end{array}$ & $\begin{array}{c}\text { Clear and } \\
\text { Bright }\end{array}$ & $\begin{array}{c}\text { Summer } \\
\text { Solstice }\end{array}$ & $\begin{array}{c}\text { Major } \\
\text { Heat }\end{array}$ & $\begin{array}{c}\text { Season } \\
\text { Frost } \\
\text { Descent }\end{array}$ & $\begin{array}{c}\text { Winter } \\
\text { Solstice }\end{array}$ & $\begin{array}{c}\text { Major } \\
\text { Cold }\end{array}$ & $\begin{array}{c}\text { Average } \\
\text { Q1 }\end{array}$ \\
& Comfort & $87.60 \%$ & $97.30 \%$ & $94.55 \%$ & $95.45 \%$ & $93.44 \%$ & $88.89 \%$ & $92.87 \%$ \\
& Cold or Hot & $12.40 \%$ & $2.70 \%$ & $5.45 \%$ & $4.55 \%$ & $6.56 \%$ & $11.11 \%$ & $7.13 \%$ \\
\hline \multirow{2}{*}{ Q2 } & Not Required & $93.02 \%$ & $98.63 \%$ & $98.18 \%$ & $93.94 \%$ & $96.72 \%$ & $93.65 \%$ & $95.69 \%$ \\
& Need Clothes & $6.98 \%$ & $1.37 \%$ & $1.82 \%$ & $6.06 \%$ & $3.28 \%$ & $6.35 \%$ & $4.31 \%$ \\
\hline
\end{tabular}

\subsection{Comparing the Change Trend of Tactile Assessment Indices}

Since PMV is highly influenced by seasonal changes, analysis of seasonal fluctuations is essential. Therefore, we compared the PPD and user data for each season. Figures 9 and 10 express the average PPD for each time-point and comfort dissatisfaction rate. The point with the least difference in Gang-neung was major cold. The difference between the two indicators was $1.94 \%$, and this was the only point classified where the user's dissatisfaction rate was higher than the PPD. As the period drew closer to winter, such as frost descent and the winter solstice, the difference between the data became more pronounced, showing a maximum difference of $25.09 \%$. The difference between the data for all seasons was $11.59 \%$, and it could be seen that the PPD fluctuated sharply as the cold season in autumn and winter was closer than in the spring and summer seasons. Through this analysis result, it could be seen that there was an error of $11.5 \%$ between the PPD and the user evaluation result.

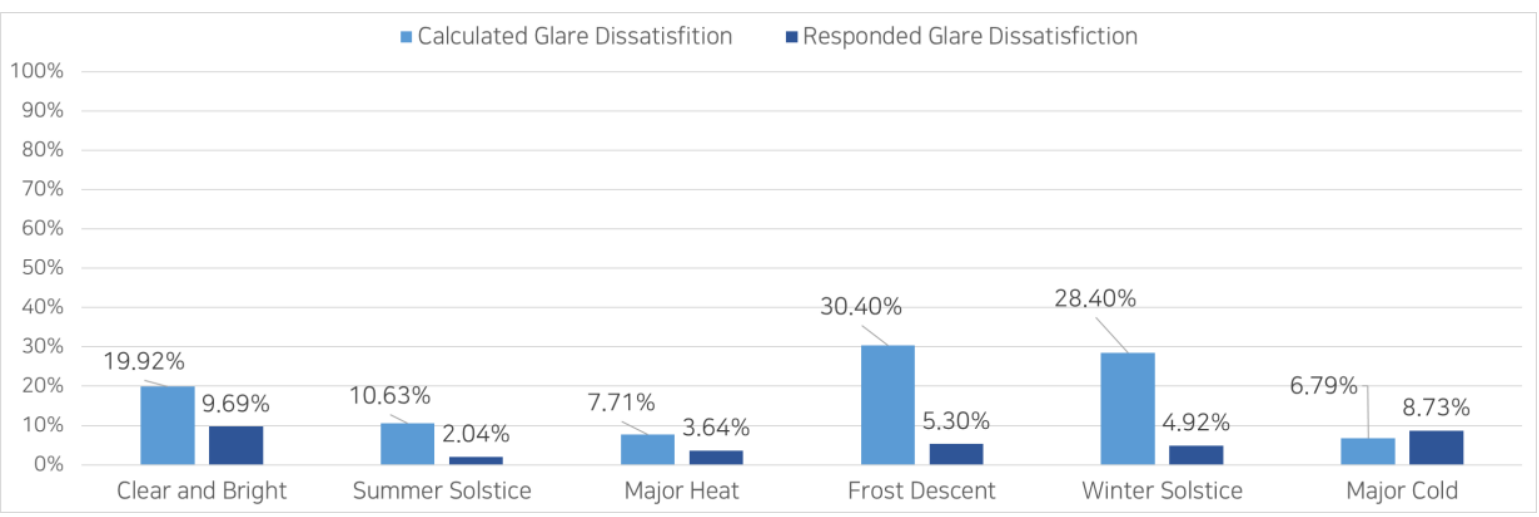

Figure 9. Comparison of user response data and PPD in the Gang-neung Hanok. 


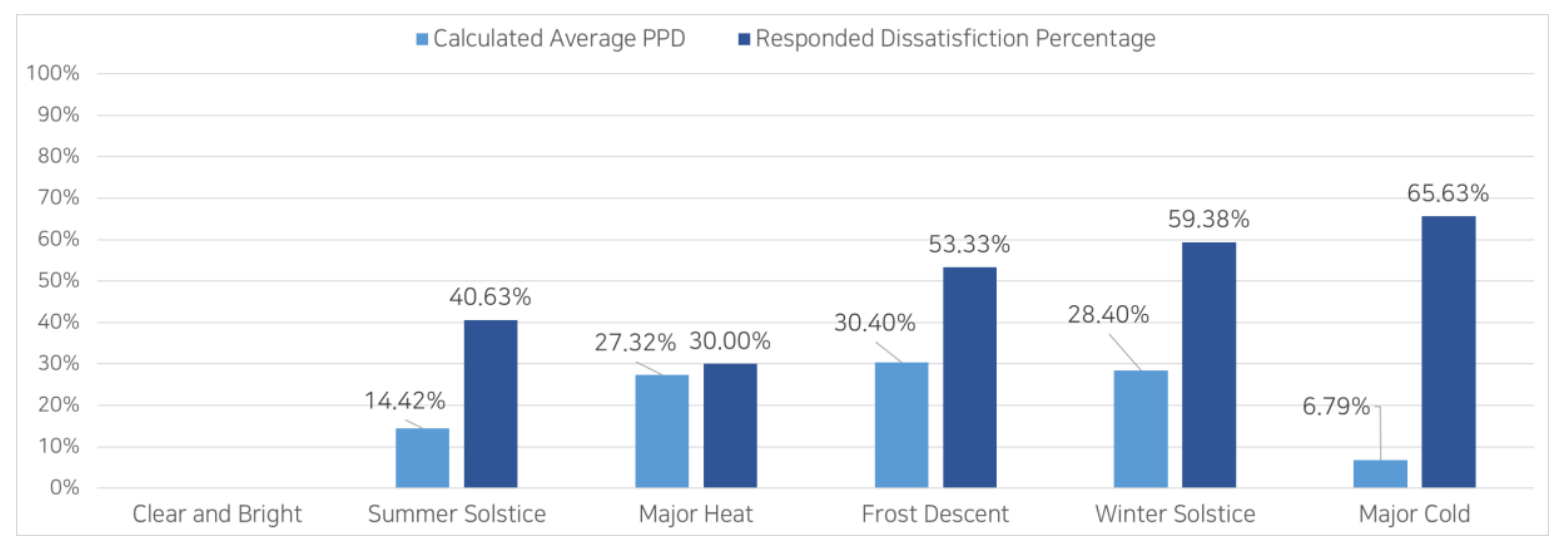

Figure 10. Comparison of the User response data and PPD in the Hwa-sun Hanok.

Hwa-sun also showed that the season with the least difference between the two data was major cold, and the proportion of user respondents was $2.68 \%$ higher. On the other hand, all seasons except major heat showed a difference of more than $20 \%$, and a maximum difference of $58.84 \%$. Hwa-sun's PPD and user data showed a very large difference at $28.33 \%$ on average. It also showed a sharp trend of fluctuations in PPD in winter, and accordingly, the dissatisfaction rate of users rapidly rose.

Overall, it was found that PMV could detect differences in the comfort of indoor thermal environments according to the Hanok structure. However, it also turned out that the actual comfort of the user could not be accurately evaluated. In the Gang-neung buildings, the satisfaction rate was about $11.5 \%$ higher than the result of PMV, while Hwasun showed a $28.3 \%$ lower-than-average value. Through the analysis result, to utilize PMV, the range of criteria used for evaluation must be supplemented.

\subsection{Analysis Results}

This research was conducted for the purpose of supplementing the items that indirectly evaluate the user's senses among the evaluation items of KS A 6300. Pursuant to the purpose, all indices presented in KS A 6300 were analyzed to extract items that perform indirect evaluation of human senses. An evaluation method that could replace the extracted Hanok evaluation items was explored, and finally, the research result was derived that direct user sensory assessment was possible through PMV and DGP indicators. In order to verify the two indices, a building to be analyzed with environmental similarity was selected and environmental data related to PMV and DGP were collected. Then, each sensory evaluation index was calculated using the measured environmental data, and the applicability of the quantitative evaluation index was analyzed by comparing them.

As a result of comparing DGP and PMV, the probabilities of glare based on DGP for both buildings were lower than those of real users. However, the errors of the two targets were similar, at $7-8 \%$. These results are believed to be due to the similarity of users according to the uses and methods of use of the two Hanok sites. In order to increase the possibility of institutional application of DGP, a method to correct the error is needed. It is judged that it should be supplemented based on user characteristics (whether wearing glasses, eyesight, sensitivity to light stimuli, etc.) that exert influence on the user's light environment.

On the other hand, despite the similarity of users, the PPD derived through PMV and the dissatisfaction rate of the user's tactile comfort showed different evaluation results. In Gang-neung, the difference between the PPD and the user's dissatisfaction rate was generally under $20 \%$, and the derived analysis result showed that the actual user's dissatisfaction rate was mostly lower than the PPD. On the other hand, in the case of Hwa-sun, the user dissatisfaction rate was generally higher than that of the PPD. This phenomenon was due to the difference in architectural structure between the two targets. Hwa-sun used the traditional wooden structure, so that the wall thickness was thin. However, because the 
Gang-neung Hanok used a reinforced-concrete structure, the wall was thick. Such building features were reflected in the calculated results. This means that PMV could perform a general evaluation of the thermal environment of Hanok, because PMV was able to detect the low thermal performance of Hwa-sun.

However, the weakness was also derived that DGP and PMV could not accurately assess human sensory comfort. The two evaluation indicators did not reflect detailed variables, such as building facilities, ventilation time, user space occupancy rate, and hours of living. Therefore, in order to apply the two indicators to the KS standard, it is necessary to increase the precision of the DGP and PMV criteria based on controlled space and environment using testbeds. If precise comfort assessment of DGP and PMV becomes possible through the above research step, it is judged that they could be applied to the KS standard.

\section{Conclusions and Suggestion}

\subsection{Conclusions}

In general, it is recognized that the advantages of vernacular buildings mainly exist in the health and historical fields. Due to this conventional wisdom, the KS standard prescribed in Korea was mainly based on content that judges the architectural performance of Hanok. Obviously, vernacular buildings' architectural performance is inevitably lacking compared to modern buildings. However, the concept of comfort should be evaluated based on human senses. Therefore, the assessment should be performed in assessment indices of human sense. This means that the content presented in KS A 6300 should go beyond simply estimating architectural performance, and an estimation tool incorporating the concept of human sensory experience should be introduced.

Therefore, this research attempted to complement KS A 6300, and to present the possibility of assessing comfort. First of all, human sensory assessment indices were extracted by analyzing the established KS Hanok standard. Then, PMV and DGP were selected as final assessment indices by searching estimation indicators that could quantitatively evaluate the derived items. Next, the chosen indicators were compared with user evaluation results for Hanok residences in two sites to examine the availability of the selected indices. As a result, if the indicator's criteria were corrected through a controlled environmental test, the two indices could be used in the KS standard. As a result, some parts of PMV and DGP reacted insensitively to the actual user's response, or even produced slightly heterogeneous results. However, the user's comfort-related response trend and the change trend of the two indicators had similarities. These results can lead to conclusion that, although the precision of evaluation of the two comfort indices was low, the category of comfort could be evaluated. In addition, if the indicator's criteria were corrected through a controlled environmental test, precise comfort evaluation through these two indices is likely to be possible. Furthermore, if such research continues, it is expected that the institutional performance of the KS certification system will also be continuously improved.

\subsection{Limitation and Suggestion}

This research was conducted in terms of spatial comfort that could be analyzed numerically among various values of vernacular architecture. Of course, the humanities and social values of traditional architecture cannot be ignored. Thus, the qualitative values were excluded from the study, because it was impossible to review them through specific comparative analysis. This aspect could be pointed out as a limitation of the research. In addition, the fact that complete user controls of indigenous architecture were not achieved, could also be regarded as a weak point. Nevertheless, the result that the comfort assessment indices had a similar tendency to the user responses would be seen as an encouraging fact in proving the validity of this study. Thus, the value of vernacular architecture could be expressed as a quantitative comfort factor, if the research direction is continuously carried out. 
Accordingly, it is believed that comfort assessment will become a medium that can prove the value of traditional architecture through quantitative evaluation for researchers conducting studies related to the value of traditional architecture. In addition, it is expected that an indirect comparison will be possible with respect to the pros and cons of traditional architecture in various countries, if the implementation method of the study can be applied to various styles of indigenous architecture. Therefore, this study is meaningful as a basic dataset for evaluating the practical and intrinsic values of such traditional architecture.

However, there are also some limitations that need to be improved with continuous implementations of this study. First of all, it can be seen as one of the limitations of the study that the search for assessment indices for auditory and olfactory comfort specified in the evaluation items of the KS was not performed. In addition, user data should have been collected for various types of Hanok. However, it was recognized as a limitation of the study that it was not possible to collect completely controlled data, due to the limitations of real-life conditions. Due to these limitations, it cannot be said that the supplementation of the comfort evaluation system for KS A 6300 has been properly performed. Therefore, it could be judged that the weaknesses of KS A 6300 can be supplemented through follow-up studies, if these parts are supplemented by ongoing research.

Author Contributions: S.-J.C. and S.-H.H. designed the research settings; S.-J.C. performed the evaluations; S.-J.C. and S.-H.H. analyzed the data; S.-H.H. verified the analysis results; S.-J.C. and S.-H.H. wrote the paper. All authors have read and agreed to the published version of the manuscript.

Funding: This research was funded by Ministry of Land and Transport Affairs of the Korean Government (Project No: 21AUDP-B128638-05).

Institutional Review Board Statement: Not applicable.

Informed Consent Statement: Not applicable.

Acknowledgments: This research was supported by a grant from the Urban Architecture Research Program (Technology Development of Design and Construction for Large-Space Hanok over $10 \mathrm{Me}-$ ters, Development of Hanok Technology, Phase III).

Conflicts of Interest: The authors declare no conflict of interest.

\section{References}

1. Koh, G.; Kim, J. A Study on the Characteristics of Ecological in Contemporary Architecture. J. Archit. Inst. Korea 2011, $27,135-142$.

2. Boik, J.C. Science-Driven Societal Transformation, Part III: Design. Sustainability 2021, 13, 726. [CrossRef]

3. Røstvik, H.N. Sustainable Architecture-What's Next? Encyclopedia 2021, 1, 293-313. [CrossRef]

4. López, C.D.; Carpio, M.; Martín-Morale, M.; Zamorano, M. A Comparative Analysis of Sustainable Building Assessment Methods. Sustain. Cities Soc. 2019, 49, 101611. [CrossRef]

5. Wang, J. A Study on Comparison in Green Building Certification System of Korea, China, and United States-Focused on the Ecological Environment Related Items. Master's Thesis, Hanyang University, Seoul, Korea, 2018.

6. Min, J. A Study on Comparison in Green Building Certification System of Korea, US, and Japan-Focus on Non-Residential Green Remodeling. Master's Thesis, Kongju University, Gongju, Korea, 2016.

7. Kim, G.; Lee, J. The Impact of Historic Building Preservation in Urban Economics: Focusing on Accommodation Prices in Jeonju Hanok Village. Sustainability 2020, 12, 5005. [CrossRef]

8. Kim, Y. The change of Donam district in the outer area of Dongdaemun. J. Seoul Stud. 2009, 37, 1-46.

9. Korean Standard, KS A 6300-1 'Examination Method for Hanok-Part 1: Comfort'. 2017. Available online: https://e-ks.kr/ streamdocs / view/sd;streamdocsId=72059207499370607 (accessed on 26 April 2021).

10. Korean Standard, KS A 6300-2 'Examination Method for Hanok-Part 2: Environmental Properties'. 2017. Available online: https:/ / e-ks.kr/streamdocs/view/sd;streamdocsId=72059213624417319 (accessed on 26 April 2021).

11. Schwartz, Y.; Rasian, R. Variations in results of building energy simulation tools, and their impact on BREEAM and LEED ratings: A case study. Energy Build. 2013, 62, 350-359. [CrossRef]

12. Doan, D.T.; Ghaffarianhoseini, A.; Naismith, N.; Zhang, T.; Ghaffarianhoseini, A.; Tookey, J. A critical comparison of green building rating systems. Build. Environ. 2017, 123, 243-260. [CrossRef]

13. Lee, M.; Cheon, D.; Han, S. A Technical Assessment of Comfort Performance of Hanok Using Comparative Field Surveys between Experts and Users. Sustainability 2020, 12, 10315. [CrossRef]

14. Comfortable Low Energy Architecture. Available online: https://new-learn.info/packages/clear/about/partners.html (accessed on 6 May 2021). 
15. Korean Standard, KS A ISO 7730 'Ergonomics of the Thermal Environment-Analytical Determination and Interpretation of Thermal Comfort Using Calculation of the PMV and PPD Indices and Local Thermal Comfort Criteria'. Available online: https:/ / e-ks.kr/streamdocs/view/sd;streamdocsId=72059212310259368 (accessed on 28 April 2021).

16. Zare, S.; Elahi Shirvan, H.; Hemmatjo, R.; Nadri, F.; Jahani, Y.; Jamshidzadeh, K.; Paydar, P. A comparison of the Correlation between Heat Stress Indices (UTCI, WBGT, WBDT, TSI) and Physiological Parameters of Workers in Iran. Weather Clim. Extrem. 2019, 26, 100213. Available online: https://www.sciencedirect.com/science/article/pii/S2212094717302037 (accessed on 26 April 2021). [CrossRef]

17. Choe, S. A Study on the Spatial Applicability for Buildings by Analyzing Daylight Performance of Microalgae Windows. Master's Thesis, Chonnnam University, Gwangju, Korea, 2020.

18. Yun, G.; Cho, S.; Kim, K. Daylighting Performance Evaluation based on Visual Environment Criteria in an Office Spaces. J. KIAEBS 2011, 52, 230-233.

19. Park, J.; Lee, Y.; Kim, D. A Parametric Analysis for Daylighting Driven Design Optimization of Office Buildings. J. Archit. Inst. Korea 2015, 31, 21-28.

20. Cheong, S.-I.; Sheng, N.-L.; Kim, D.-H.; Lee, J.-K.; Hwang, Y.-J.; Park, J.-H.; Seo, S.-J. Analysis of Comfortable Environment in the Classroom with Humidification and Ventilation in Winter. Korean J. Air-Cond. Refrig. Eng. 2009, 21, $402-408$.

21. Kang, K.; Lee, K. Evaluation of Thermal Comfort on Applying Double-Skin Facade System in Office Space by PMV Index. J. SAREK 2010, 6, 1288-1293.

22. Wang, Y.; Liu, Y.; Song, C.; Liu, J. Appropriate indoor operative temperature and bedding micro climate temperature that satisfies the requirements of sleep thermal comfort. Build. Environ. 2005, 92, 20-29. [CrossRef]

23. Maureen, T.; Jaime, S.; Jeremy, P. Evaluation of Thermal Comfort Standards in Office Buildings of Chile: Thermal Sensation and Preference Assessment. Build. Environ. 2020, 183, 107158. Available online: https://www.sciencedirect.com/science/article/pii/ S0360132320305321 (accessed on 26 April 2021).

24. Gilani, S.I.H.; Khan, M.H.; Pao, W. Thermal Comfort Analysis of PMV Model Prediction in Air Conditioned and Naturally Ventilated Buildings. Energy Procedia 2015, 75, 1373-1379. [CrossRef]

25. Fabbri, K. Thermal comfort evaluation in kindergarten: PMV and PPD measurement through datalogger and questionnaire. Build. Environ. 2013, 68, 202-214. [CrossRef]

26. Grasshopper Ladybug. 2017. Available online: https://www.ladybug.tools (accessed on 26 April 2021).

27. Cheng, W.; Spengler, J.; Brown, R.D. A Comprehensive Model for Estimating Heat Vulnerability of Young Athletes. Int. J. Environ. Res. Public Health 2020, 17, 6156. [CrossRef]

28. Cheung, T.; Schiavon, S.; Parkinson, T.; Li, P.; Brager, G. Analysis of the accuracy on PMV—PPD model using the ASHRAE Global Thermal Comfort Database II. Build. Environ. 2019, 153, 205-217. [CrossRef]

29. Broday, E.E.; Ruivo, C.R.; da Silva, M.G. The use of Monte Carlo method to assess the uncertainty of thermal comfort indices PMV and PPD: Benefits of using a measuring set with an operative temperature probe. J. Build. Eng. 2021, 35, 101961. [CrossRef]

30. Zhang, D.; Boyi, Q.; Pengfei, L.; Zhoujian, A. Comprehensive evaluation and optimization of rural space heating modes in cold areas based on PMV-PPD. Energy Build. 2021, 246, 111120.

31. Bian, Y.; Luo, T. Investigation of visual comfort metrics from subjective responses in China: A study in offices with daylight. Build. Environ. 2017, 123, 661-671. [CrossRef]

32. Bian, Y.; Luo, J.; Hu, J.; Liu, L.; Pang, Y. Visual discomfort assessment in an open-plan space with skylights: A case study with POE survey and retrofit design. Energy Build. 2021, 248, 111215. [CrossRef] 